\title{
AFROS, ACTIVISM, AND AFFINITY: THE POLITICIZATION OF NATURAL BLACK HAIR, RACISM, AND A SENSE OF BELONGING IN THE MULTICULTURAL GREATER TORONTO AREA
}

\author{
by \\ Jasmine Homer, BA, University of Toronto, 2016
}

\author{
A Major Research Paper \\ presented to Ryerson University \\ in partial fulfillment of the requirements for the degree of \\ Master of Arts \\ in the Program of \\ Immigration and Settlement Studies
}

Toronto, Ontario, Canada, 2018

(C) Jasmine Homer 2018 


\section{AUTHOR'S DECLARATION FOR ELECTRONIC SUBMISSION OF A MAJOR RESEARCH PAPER (MRP)}

I hereby declare that I am the sole author of this Major Research Paper. This is a true copy of the MRP, including any required final revisions, as accepted by my examiners.

I authorize Ryerson University to lend this MRP to other institutions or individuals for the purpose of scholarly research.

I further authorize Ryerson University to reproduce this MRP by photocopying or by other means, in total or in part, at the request of other institutions or individuals for the purpose of scholarly research.

I understand that my MRP may be made electronically available to the public.

Jasmine Homer 


\title{
AFROS, ACTIVISM, AND AFFINITY: THE POLITICIZATION OF BLACK NATURAL HAIR, RACISM, AND A SENSE OF BELONGING IN THE MULTICULTURAL GREATER TORONTO AREA
}

\author{
Jasmine Homer \\ Master of Arts 2018 \\ Immigration and Settlement Studies \\ Ryerson University
}

\begin{abstract}
This research study explores the natural hair textures of six Black/mixed-race women as a symbol of activism in the Greater Toronto Area (GTA), where natural Black hair continues to be discriminated against in public and private spheres. While all six women experienced racism in the GTA, intergenerational knowledge from family played a larger role in shaping their negative perceptions of their own hair, and how members of the dominant group may perceive their hair. Their experiences were assessed alongside their opinions on Canada's well-known Multiculturalism Act (1982, c.24) which seeks to preserve and enhance multiculturalism. While all six women believe that cultural celebrations (e.g. Caribana, Taste of the Danforth, etc.) are a demonstration of The Act in play, they all find that The Act is ineffective in bridging the gap between ideology and practice, and therefore does not facilitate social inclusion between members of the dominant group and racialized 'Others'.
\end{abstract}

\section{Key Words:}

Racism in Toronto; Natural Hair; Activism; Multiculturalism Act; Social Inclusion 


\section{Table of Contents}

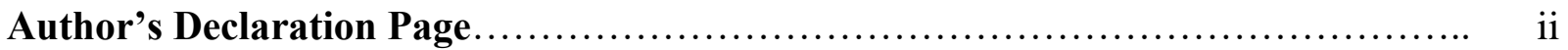

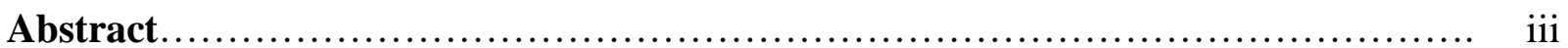

List of Appendices. $\ldots \ldots \ldots \ldots \ldots \ldots \ldots \ldots \ldots \ldots \ldots \ldots \ldots \ldots \ldots \ldots \ldots \ldots \ldots \ldots \ldots \ldots, \mathrm{V}$

\section{Chapter 1}

Introduction.

\section{Chapter 2}

Literature Review............................................................ 4

History of Hair Alteration ........................................................................ 4

The Politics of Black Hair............................................................... 10

Anti-Black Racism in the Toronto GTA.................................................. 16

Intersectionality \& Critical Race Theory ..................................................... 21

\section{Chapter 3}

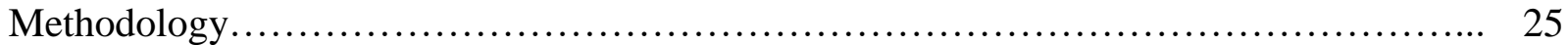

\section{Chapter 4}

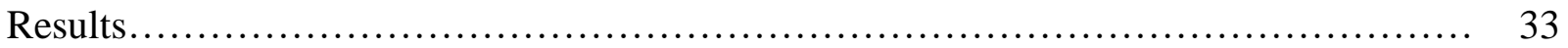

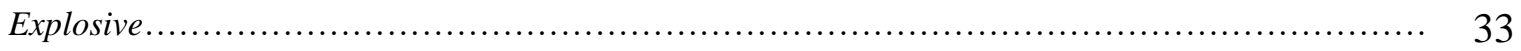

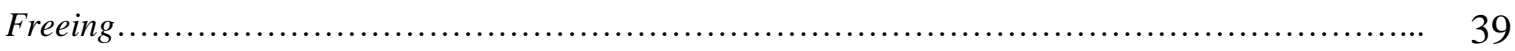

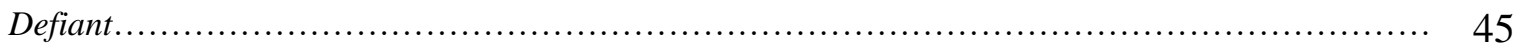

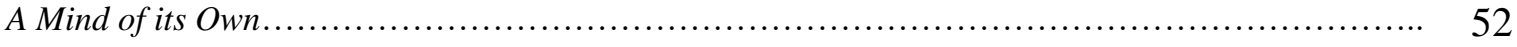

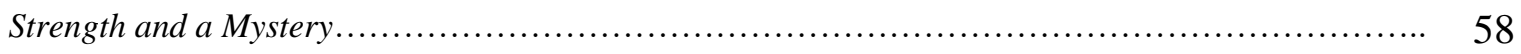

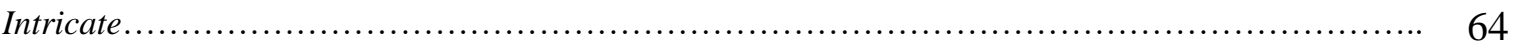

\section{Chapter 5}

Analysis............................................................... 71

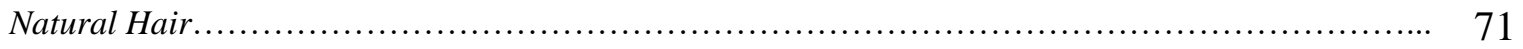

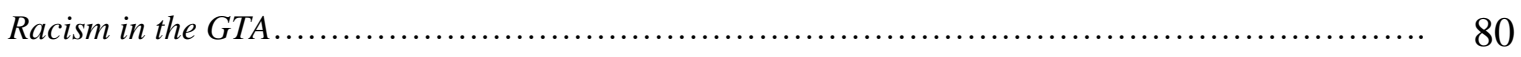

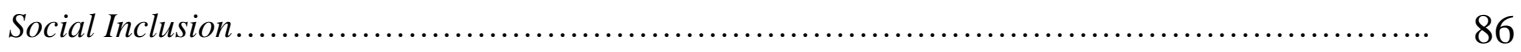

\section{Chapter 6}

Conclusion.

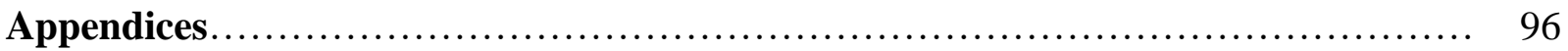

References............................................................ 109 


\section{List of Appendices}

Appendix A: $\quad$ Recruitment Letter.............................................. 96

Appendix B: $\quad$ Consent Agreement............................................. 97

Appendix C: $\quad$ Demographic Questionnaire.................................... 104

Appendix D: $\quad$ Interview Guide............................................. 106 


\section{Chapter 1 - Introduction}

When people are asked to unpack what it means to be Canadian, the term 'multicultural' is often used. Compared to their neighbours to the South, Canadians are considered to be more tolerant to racial and cultural differences and therefore offer a more welcoming attitude towards immigrants whose appearance and norms differ from the Anglo-Saxon dominant group (Paris, Apr. 27, 2018). While it may be true that racialized people may face less blatant racism in Canada compared to the US, believing that racism is not a notable issue in Canada is wildly inaccurate. As Melissa Gismondi (Aug. 18, 2017) says, "Canadians have a tendency not to be less racist than Americans, but less loud about it." Racism in Canada tends to be more subtle and insidious, often disguised as ignorant or insensitive comments. Considering Canadians continue to praise their culture of tolerance that has been enacted into federal legislation in the form of the Multiculturalism Act (1985), it may seem hypocritical that racialized people are routinely discriminated against for displaying and wearing cultural symbols in the most multicultural cities like Toronto and the surrounding Greater Toronto Area (GTA).

One indicator of cultural/racial difference that continues to be the target of racism in the Toronto GTA is the natural hair textures of Black women. As insignificant as hair may seem to some, Black women who wear their hair in its natural state (i.e. free from chemical straightening agents) regularly experience racism and/or prejudice against their hair. Based on centuries of racism and oppression, the natural hair of Black women is still largely considered to be less professional, less attractive, and generally less appealing than Eurocentric styles and textures. Essentially, Black women with kinky hair are less appealing than Black women with straight and smooth hair in a Eurocentric society, such as Canada, that continues to value Whiteness over 
Blackness. This preference goes beyond aesthetics and has real consequences on the economic and psychological well-being of Black women who have decided to embrace their natural hair.

The decision to "go natural" is usually not an easy one. Foregoing the chemical perm and facing the societal consequences challenges these deeply embedded beliefs within Western societies that are perpetuated by Black and non-Black people alike. "Going natural" is arguably an act of resistance against a history of colonialism and a reclamation of Blackness as beautiful while Blackness continues to be denounced in contemporary Canadian society. In recent years, we have seen a major influx in the number of Black women embracing their natural hair which has given rise to a Natural Hair community and a Natural Hair Movement that seek to create a positive image of natural hair and beauty within the Black community (Ellis-Hervey et al., 2016). The issue of systemic racism and unprovoked or unjustified violence being unleashed onto Black people in North America has also led to the establishment of Black Lives Matter, a sociopolitical movement founded by three queer Black women in response to the acquittal of George Zimmerman in the murder of Trayvon Martin in 2012 (BlackLivesMatter.com, n.d.). Both movements challenge and undermine racism towards Black bodies and encourage Black people to own the space and the skin they are in - to be "unapologetically Black." While wearing their hair in its natural state is not a necessary component of being "unapologetically Black," refusing to wear it in unnatural, often harmful Eurocentric styles is, in itself, an important form of activism that challenges stereotypes about Afrocentric hairstyles and can increase tolerance for Blackness in the Toronto GTA.

This Major Research Paper will explore instances of racism faced by six Black/mixed-race Black women who live in the Toronto GTA and wear their hair in its natural state. Their opinions towards their hair as a form of activism and how they believe natural Black hair is perceived in the GTA will be analyzed alongside their opinions on Canada's Multiculturalism Act and whether it 
has a positive effect on the day-to-day lives of racial minorities. The major themes that will be explored in this MRP are: natural hair, racism in the GTA, and social inclusion. Because this study is an exploration of individual experiences and perceptions of the subject matter, I have no proposed hypotheses. My primary research question is: do racist events experienced by Black women with natural hair influence their opinions on the legitimacy of the Multiculturalism Act in Canada, and is their sense of belonging to the GTA affected? The individualistic nature of this research makes this a phenomenological study but given the fact that each participant will have different opinions on racism, their hair as a form of activism, and their sense of belonging to the GTA, more than one conclusion must be considered. 


\section{Chapter 2 - Literature Review}

The political significance of Black natural hair as a tool for revolution has been well documented since Angela Davis sported her infamous afro in solidarity with the Black Power movement in the United States during the 1960s and 1970s (Gillespie, 2013; Johnson \& Bankhead, 2013; Johnson, 2016). Black natural hair became heavily politicized as Black people in the U.S. increasingly abandoned the use of thermal and chemical straightening products or wearing wigs/weaves, and embraced their natural hair, thereby embodying a resistance to colonial, Eurocentric (i.e. White female) standards of beauty (Barnett, 2016; Dash, 2006; Dunn, 2015; Johnson \& Bankhead, 2013; Rosette \& Dumas, 2007; Weitz, 2001). This widespread movement was about more than just rejecting dominant beauty standards - it was about rejecting racism and White supremacy, the idea that "White is Right", and that socioeconomic success and overall happiness was determined by one's appearance. Specifically, Black people that more closely

resembled White Europeans have historically been favoured over those that resembled African slaves, and therefore enjoyed more opportunities to acquire valuable social, human, and economic capital (Barnett, 2016; Dash, 2006; Dunn, 2015; Johnson \& Bankhead, 2013; Rosette \& Dumas, 2007; Weitz, 2001). This narrative was established during colonialism and served to reinforce the racial hierarchy on which the success of colonialism depended.

\section{History of hair alteration}

Scholars have recognized that a sense of shame towards ones' physical appearance has been internalized by the descendants of slaves and has permeated Black consciousness around the globe (Barnett, 2016; Bellinger, 2012; Donaldson, 2012; Ellis-Hervey et al., 2016; Gillespie, 2013; Robinson, 2011). A common practice of Europeans during the enslavement process of Africans 
was to shave the heads of the slaves, both male and female. During this process, Africans were stripped of their identities, their culture, and their individuality. In African culture, hair is an important symbol that conveys information about a person including tribal heritage, marital status, social rank, age, and much more (Bellinger, 2007). Hair was, and still is styled in a plethora of ways that varies across the African continent and may be styled differently to mark special occasions. Given the intense social and cultural significance of hair to Africans, the process of being scalped was dehumanizing and therefore, a useful tactic to break their spirits and ensure subordination (Bellinger, 2007). The shame felt through the loss of their hair was coupled by a devaluation of other physical characteristics as well. Blackness became the antithesis of beauty. Slave women were instructed by the slave masters to cover up their scalped heads with rags and cloths as their hair was considered "ugly" and "unsightly" and they frequently had parasites, dandruff, and bald spots as a result of poor hygiene and harmful chemicals in soaps (Donaldson, 2012). They were not given any time to tend to their hair, nor their personal hygiene, so slave women had no choice but to maintain a shaved head or live with dirty, matted hair - a look that traditionally suggested promiscuity, little or no morals, or being “crazy” (Bellinger, 2012).

Certain slaves were not subjected to the same mistreatment, however. Those that were lighter-skinned and had physical characteristics that more closely resembled those of White women (i.e. slender noses, thinner lips, a slimmer physique, and straighter hair) were given preferential jobs on the plantations, such as maids or cooks in the master's house known as the "Big House" (Barnett, 2016). Most often, these slaves were the products of the White masters raping their slave women. Because these slaves were frequently in the presence of their masters and visitors, they were granted more time for grooming so that they could appear more presentable. 
Female slaves working in the Big House were awarded time and products to style their hair, and oftentimes were given wigs to wear that resembled those worn by White women at the time.

Because the lighter-skinned slaves were considered by the masters to be more physically appealing and were thus given preferential treatment over those with darker skin, a shade-based hierarchy was reinforced, confirming Whites place at the top and Blacks at the bottom, while those that were mixed-race enjoyed some of the privileges that came along with Whiteness (Donaldson, 2012). Mixed-race women that had naturally straighter and softer-looking hair possessed what came to be known as "good hair", while darker-skinned women that had shorter, courser, and more tightly-coiled hair had "bad hair" (Barnett, 2016; Bellinger, 2012; Ellis-Hervey et al., 2016; Gillespie, 2013; Johnson, 2016; Johnson \& Bankhead, 2013; Johnson et al., 2017; Robinson, 2011; Rock et al., 2009; Rosette \& Dumas, 2007; Saint-Louis, Aug. 26, 2009; Weitz, 2001; Wheeler, 2017). Slaves with a lighter complexion and straighter hair were assigned a higher value by the slave master than their darker-skinned counterparts and commanded higher prices at auctions, thus demonstrating that features that more closely resembled those of the Europeans were more socially and economically valuable (Ellis-Hervey et al., 2016). By internalizing society's preference for Whiter skin and features, Blacks developed an inferiority complex and sought out methods to straighten their hair, including using dangerous chemicals like lye and "conk" (Barnett, 2016). Hair straightening and assimilating to White female European beauty standards over time became normalized in the Black community.

It was not until the end of the $19^{\text {th }}$ century and beginning of the $20^{\text {th }}$ century that products specifically designed for the hair of Black women came into existence, the most notable tool being Madame C.J. Walker's hot comb (Barnett, 2016). The iron comb was heated to a scalding temperature and brushed through the hair to lengthen and loosen tight coils, thus turning "bad hair" 
into "good hair". It was a common occurrence for Black women to suffer from burns on their scalps and ears and develop fried hair and even bald spots from using the hot comb, but its usage became customary of Blacks as they (and wider society) considered straighter hair to be more beautiful. Because Black women had to alter their physical appearance to be considered beautiful in White Eurocentric society, Black women developed a sense of self-hatred and shame for their natural physical characteristics, which has manifested across generations and still exists today (Johnson \& Bankhead, 2014).

The Black hair care industry became a multi-billion-dollar industry in the $20^{\text {th }}$ century supplying Black women with a plethora of products and tools designed to straighten and lengthen coiled, kinky hair or cover it up entirely with wigs and weaves. Chemical relaxers continued to be highly valued for its hair-straightening abilities, becoming popularly known as "creamy crack", a euphemism that compares the addictive nature of the product to crack cocaine. A touch-up was required every six to eight weeks to maintain the hairstyle, but oftentimes women would reapply the product much more often. In Chris Rock's documentary Good Hair (2009), many of the women interviewed admitted to using the "creamy crack" more often than recommended to maintain their straightened hair. One woman revealed that she would book her salon appointment for a reapplying of relaxer as soon as she thought she felt new roots growing in (Rock et al., 2009). Using chemical relaxers became a sort of Rite of Passage for the Black community in Western nations, especially North America. In Rock's documentary (2009), children as young as two and three years old were seen getting chemical relaxers, or "Kiddie Perms" alongside their mothers. One three-year-old child was asked by Rock if she likes getting a perm, to which she shook her head "no". She was then asked why she continues to get perms to which she replied, "because, everyone needs a perm" (Rock et al., 2009). 
Using chemical relaxers continues to be one of the most popular ways of attaining straightened hair although the dangers of using such products are well known to health and beauty experts and the Black community. Although many noteworthy improvements have been made to chemical relaxers since they were first introduced in the early 1900s, they still contain many of the same harmful chemicals used in early-age relaxers including sodium hydroxide and calcium hydroxide. Furthermore, modern relaxers still significantly damage the hair follicles, cuticles, and scalp (Syed, Ayoub, \& Kuhajda, 1998 cited by Powell, 2011). When applied, women complain of the intense burning sensation, "as if my head was on fire" (Rock et al., 2009). If applied incorrectly or left on the scalp for too long, the hair could burn right off and result in bald patches that scab and bleed. Many of the women interviewed by Rock et al. (2009) consider the pain and health risks to be a necessary sacrifice in order to attain a physical appearance that is deemed more beautiful and more appealing to potential employers and potential romantic partners (Barnett, 2016; Bellinger, 2012; Ellis-Hervey et al., 2016; Gillespie, 2013; Johnson, 2016; Johnson \& Bankhead, 2013; Johnson et al., 2017; Robinson, 2011; Rock et al., 2009; Rosette \& Dumas, 2007; SaintLouis, Aug. 26, 2009; Weitz, 2001; Wheeler, 2017).

The draw to chemical relaxers is made clear when considering the cost of purchasing other hair products that are less risky, including wigs and weaves. A wig or a full set of weave made from human hair can cost thousands of dollars and must be redone by a trained hair stylist every few months (Rock et al., 2009). Even though these hair coverings do not require harmful chemicals, the process of attaching the pieces to the head can be very painful. The most secure way of attaching is to braid the client's own hair very tightly to the scalp in miniature cornrows and then sew the wig or weave onto their hair. Mishaps are frequent according to the women interviewed in Good Hair (2009) who spoke about the pain of getting pricked by the sewing 
needle. Regardless of the hair styling choice, be it chemically straightened or covered by a wig or weave, Black women report spending hours in the salon each visit and spending upwards of tens of thousands of dollars annually, a difficult situation for low-income earning women (Rock et al., 2009). This internalized notion of beauty which privileges Whiteness and subordinates Blackness continues to be supported by a commodified Black hair care industry.

While Barnett (2016) and Donaldson (2012) argue that the apparent need for Black women to alter their hair texture to mirror White European hair demonstrates an internalized self-hatred and shame for their natural hair, they also warn against such an oversimplification and suggest that hair straightening has become embedded in tradition for Black women and an integral part of the Black female identity. That being said, Black women with straight hair are still considered to look more beautiful and more professional than those with natural hair styles, such as afros, twists, or dreadlocks. The "Good Hair" Study conducted by Johnson et al. (2017) measured explicit and implicit racial biases of Black and White men and women towards Black women's hair and found that the majority of the 4,163 participants, regardless of race, showed implicit bias against textured hair (i.e. natural hair styles). Furthermore, the study found that all of the Black female participants perceived a level of social stigma against textured hair. One in five Black women reported feeling social pressure to straighten their hair for work or other professional events, twice the number of White women (Johnson et al., 2017). Of the hairstyles that Black women would consider wearing to a professional event, twist-outs and dreadlocks were the least considered (28\% and 27\%, respectively), while long curls and a pixie cut were the most considered (65\% and 70\%, respectively) (Johnson et al., 2017, p. 12). Black women also reported experiencing more anxiety towards their hair than White women. For example, one in three Black women reported avoiding exercise because of concerns for their subsequent hair maintenance compared to one in ten White 
women (Johnson et al., 2017). The psychological effects of anxiety towards the presentation of Black women's hair is well documented in a number of American studies (Bellinger, 2007; Dash, 2006; Ellis-Hervey et al., 2016; Gillespie, 2013; Harris-Britt et al., 2007; Johnson et al., 2017; Johnson \& Bankhead, 2013; Robinson, 2011; Sellers et al., 2006). Black women continue to face social pressures to assimilate into North American Eurocentric society and their natural hair remains heavily politicized and potentially dividing the Black community regarding a critique of white privilege; gendered and racial notions of beauty; and a sense of authentic Black identity (Barnett, 2016; Donaldson, 2012; Ellis-Hervey et al., 2016; Gillespie, 2013).

\section{The politics of Black hair}

The political nature that has been ascribed upon natural Black hair stems from the days of slavery as discussed above, and was heightened during the Black Power era in the US during the 1960s and 1970s. Members of the Black Panther Party and activists like Angela Davis, Nina Simone, and Nikki Giovanni sparked immense controversy when they donned large, springy afros in solidarity with the movement which fought to resist racism and the treatment of Blacks as second-class citizens (Bellinger, 2007; Johnson, 2016; Saint-Louis, Aug. 26, 2009; Wheeler, 2017). The afro became a symbol of militancy and resistance to White supremacy and Eurocentric beauty standards that Black men and women were pressured to ascribe to in order to assimilate into White American society (Bellinger, 2007; Johnson \& Bankhead, 2013). People showed their racial pride by wearing their hair in its natural state and emphasizing the size and shape of the afro by picking it with combs throughout the day, the comb itself becoming a powerful symbol. By blatantly choosing to embrace what society had deemed as "bad hair", those who wore their hair in an afro were taking back their Black identity and challenging the idea that for a Black woman to be considered beautiful, she must have straightened hair (Saint-Louis, Aug. 26, 2009). 
While the Black Power movement took hold in the US, its influence quickly spread north across the Canada-US border. Canada has a deep, often silenced history of anti-Black racism and while free Blacks had settled in Canada prior to the American Revolution, the Canadian government did not remove racist restrictions based on country of origin to its immigration policy until 1967. Canadian Black Power was influenced by US activists who migrated to Canada during the 1960s (Harris, 2014). Although a radical Black population was already based in major cities like Toronto, much of the credit for organizing and founding associations is given to the involvement of Black US activists like Norman "Otis" Richmond. Members of the Black Panther Party in the US were often invited to rallies held in Canadian cities to educate Black Canadians on Black colonization and liberation in the US, thus inspiring their northern brothers and sisters to follow suit in the fight for equality (Harris, 2014). Although the political significance of the afro transcended the border and Black Canadians could be seen sporting the style as a symbol of resistance to racism in solidarity with their southern counterparts, the pan-African diasporic movement that sought to unite Blacks globally could not be fully realized. Walter Rodney blamed the Canadian Black Panther's lack of originality for the somewhat limited success of the Black liberation movement in Canada compared to the US since the Canadian leaders did not take into account their own national context (Harris, 2014). Due to this oversight, the Canadian Panthers became divided over the direction the Party should take in Canada by the end of the 1960s, resulting in a fragmentation.

As the Black Power era came to a close, the symbolism of the iconic afro reversed from a sign of black pride and militancy to an indicator of delinquency and a lack of morals (Bellinger, 2007). Once again, natural Black hair was shunned by the Black community as the need to assimilate and secure employment remained dependent on looking presentable and professional to 
a predominately White audience - a look that could be achieved by relaxing one's hair (EllisHervey et al., 2016). Chemical relaxers, thermal straightening tools, wigs, and weaves once again became a popularly conceived necessity for Black women throughout North America as their "nappy hair" was reinforced as a "badge of shame" (Bellinger, 2007, p. 66). By the early 2000s however, attitudes towards natural Black hair began to change once again. The Natural Hair Movement took hold in the US and Canada and aimed to create a positive image of natural hair and beauty within the Black community (Ellis-Hervey et al., 2016). Although natural hair continues to hold political connotations, the Natural Hair Movement seeks to downplay the image of militancy and instead, promote a culture of acceptance in which Black women can begin to think of their natural hair as beautiful, "good hair" regardless of its texture (Ellis-Hervey et al., 2016; Johnson et al., 2017). It is about "self-discovery" that gives a sense of pride and strength (Henderson, 2015). Furthermore, the widespread shift towards naturalism suggests that natural hair is now superior to straightened hair (at least in the eyes of the Black community) because "going natural" is a non-conforming behaviour that demonstrates courage (Henderson, 2015). As a result, many Black women now label themselves as "natural" even if they still alter their natural curl pattern and texture.

Since 2009, the market value of chemical relaxers in the US has declined $34 \%$ and is continuing to sink (Johnson et al., 2017). While there is greater acceptance within the Black community for natural, healthy hair and less tolerance for racism and prejudice against Black bodies, many Black women continue to straighten their hair or wear wigs and weaves for a number of reasons. Rosette and Dumas (2007) found that Black women in the workplace use hairstyles to differentiate their social class. Middle- to upper-classed Black women were more likely to wear their hair straightened or wear wigs or weaves as it conveys a more professional image in Western 
Eurocentric society, while Black women of lower rank were more likely to embrace their natural hair and resist conforming to society's preference for relaxed hair. Assuring economic security is one popular reason identified by Donaldson (2012) as to why Black women feel the need to alter their hair.

Donaldson (2012) posits that internalized shame or self-hatred should not be considered the only reason why Black women in North America do not embrace their natural hair as this would simply the issue and remove agency from many women. Other possible reasons identified by Donaldson (2012) include: the practice of following a cultural script or tradition, the impact of the media on Black women's psyche (i.e. brainwashing), or that straightened hair allows for a more manageable hair care routine. While purchasing wigs and weaves is expensive, using chemical relaxers is much more affordable (Johnson et al., 2017; Rock et al., 2009). Furthermore, caring for natural hair often requires more time, effort, and money to maintain compared to chemically altered hair (Ellis-Hervey et al., 2016). Although the Black hair care industry and mainstream companies such as Loreal, Pantene, and Revlon are increasingly devoting more resources towards natural hair care products as the market for chemical relaxers declines (Johnson \& Bankhead, 2013; Johnson et al., 2017), being 'natural' often involves using more products, and thus spending more money regularly compared to getting chemical perms (Ellis-Hervey et al., 2016).

While the Natural Hair Movement has taken hold in the Toronto GTA and natural Black hair styles can be seen in all environments and industries, scholarly literature on the subject is lacking. The vast majority of research focusses on women's exposure to the Natural Hair Movement of the 1960s and 1970s and if that had influenced their choice to go natural, or how they understand and embrace or reject the phrase "good hair" (Henderson, 2015). As a result, much of the discussion around natural hair takes place through social media, which is where I learned 
the most about it in recent years. This study will therefore add to a limited library on what "going natural" means to women living in a society that generally considers their natural hair unattractive, unprofessional, and inappropriate.

While there is considerable debate within the Natural Hair community regarding what hair styling practices and tools can be considered "natural", the agreed upon criteria is an abandonment of chemical relaxers (Ellis-Hervey et al., 2016; Henderson, 2015; Johnson, 2016). The reasons why Black women decide to "go natural" are entirely subjective and include health reasons, personal preferences, the availability of information about how to care for and style natural hair, or to make a political statement about the Eurocentric nature of Western society that continues to value Whiteness over Blackness (Ellis-Hervey et al., 2016; Johnson, 2016). Due to the multitude of reasons why Black women decide to embrace their natural hair, it cannot be said that the Natural Hair Movement is entirely political or unified. That being said, this major research paper explores the extent to which the movement can be considered a political one for the people that view natural Black hair as a political statement.

While the politicized nature of natural Black hair has always existed in Western society, the rise of sociopolitical movements such as the Natural Hair Movement and Black Lives Matter have revived the essence of racial pride and resistance to racism that manifested during the Black Power era in the 1960s and 1970s. Lurie Daniel Favors, a Black female attorney and activist based in New York City with natural hair, participated in a panel discussion titled Afros and Activism (2015) and was asked about the differences between the Natural Hair Movement of the 1960s and 1970s compared to now, to which she responded,

“... looking at afros and hair as a revolutionary space then and now, we're seeing a lot of parallels... when you choose to walk around with hair that looks so obviously antithetical to the White society and told it's unacceptable you kind of open yourself up to criticism 
and ridicule from other people and from within, I think that was true back then and I think that's true now." (Afros and Activism, 2015).

Tajh Sutton, founder of Young People of Color Inc. and another Black female with natural hair stated,

“... its' impossible to avoid politicizing our hair [Black natural] because of the status quo that exists," to which Favors followed up with, "I'm not concerned with how White people see and have politicized our hair, I'm concerned about how we have internalized those messages and how we perpetuate those messages... it ties into White supremacist ideology. We have to acknowledge that we are a walking, talking political issue." (Afros and Activism, 2015).

Because natural Black hair continues to carry significant political connotations in Western society, most members of Black Lives Matter chapters in the US and Canada have joined the Natural Hair Movement as a way to challenge the structural and systemic issues of racism that continue to devalue and criminalize Black bodies.

Black Lives Matter (BLM) is a sociopolitical movement that was founded in the US by three queer Black women - Alicia Garza, Patrisse Cullors, and Opal Tometi - in July 2013 in response to the non-indictment of George Zimmerman for the murder of Trayvon Martin (BlackLivesMatter.com, n.d.). The revolutionary hashtag \#BlackLivesMatter or \#BLM has since been used over 100 million times by Twitter users in response to state-sanctioned injustices and violence against Black bodies, particularly by police officers (Jackson, 2016). Some of the central tenants of the Black Lives Matter movement include: a commitment to restorative justice, queer and transgender affirmation, being unapologetically Black, and practicing empathy to all comrades to understand their individual contexts (Jackson, 2016). Organizers consistently point to and seek to undermine the structural and systemic issues that promote and accept the ongoing violence on Black communities in the US and globally such as institutional racism, the school to prison pipeline, mass incarceration, redlining, and the repeal of the Voting Rights Act (Austin et al., 
2016). Black Lives Matter has developed a reputation as "the new Civil Rights movement" (Jackson, 2016, p. 375) and can be expected to make known the injustices committed against Black bodies and demand that Western society reconsider how it values Black lives (Hall, 2016).

\section{Anti-Black racism in the Toronto GTA}

Although not explicitly stated, being "unapologetically Black" involves embracing natural Black hair and positioning it as beautiful and acceptable in Western society. That being said, having natural hair is not required to demonstrate racial pride and in essence, be "unapologetically Black” (Stevenson, 2015). According to Damon Young (Feb. 26, 2016), "To be unapologetically Black, you have to be proud of an unembarrassed by Blackness. And this doesn't mean just embracing yourself. It means removing negative connotations possessed with entities associated with Blackness." This idea mirrors the ideology of the Black Power movement that called for a rejection of Westernization and hegemonic normative societies that devalued the Black race (Henderson, 2015). Rather than submitting to Western customs and instructions on how to act, look, and think, being "unapologetically Black" encourages Black people to reconnect with their ancestral cultures and traditions and to present themselves in ways that conveys racial pride. It is about no longer dedicating energy towards "trying to assimilate into a culture that does not welcome [Black people]," but rather loving oneself in the face of racism (Blake, Apr. 21, 2018). It involves stepping outside of the "White gaze" and not concerning oneself with what the general White populace will think about an action, style, or even food preference that may be considered stereotypically "Black" and create anxiety (Blake, Apr. 21, 2018; Young, Feb. 26, 2016).

There is no longer a "back to Africa" mentality that characterized much of the historic Black pride movements. Instead, being "unapologetically Black" today involves asserting ones' right to live in predominately White societies while also ignoring the "White gaze" and loving 
ones' "Blackness". Embracing natural hair and refusing to style it in typical Eurocentric ways (i.e. straight and smooth) is only one way to demonstrate a love for ones' "Blackness". While being "unapologetically Black" can be more easily defined, performing "Blackness" is much more subjective and individualized, and demonstrates the intersecting oppressions and life experiences that are unique to each individual. The complexity of understanding and performing "Blackness" will be uncovered in this study as it pertains to the participants.

The Natural Hair Movement rejects the hegemony of Eurocentric standards of beauty and challenges Western society to abandon these archaic views, thus thwarting the premise that certain natural hairstyles are unprofessional. When a Black Grade 8 student in Toronto was sent home from school for wearing her hair in its natural afro deemed "too poofy and unprofessional" in 2015, the Toronto chapter of BLM organized a demonstration outside the Toronto District School Board's headquarters with signs that read "Black is Beautiful" and "Big, Black, Beautiful Hair" to protest the Board's treatment of students of colour (Stevenson, 2015). Some of those interviewed during the demonstration recounted their own experiences with anti-Black racism directed towards their natural hair in school and the workplace, all of them citing the problem that natural Black hair is still deemed unprofessional and Black women are still inadvertently forced to assimilate to Western social standards and wear straightened hair to ensure economic security (Stevenson, 2015). One woman stated she had been fired from Wonderland a few years prior because she wore her hair in dreadlocks and that was considered an "extreme hairstyle" and a violation of the company dress code (Stevenson, 2015).

Assimilation continues to be an issue for all visible minority groups, particularly recent immigrants who often feel pressured to hide their cultural heritage from the "White gaze" (Gilkinson \& Sauvé, 2012). It is widely believed that assimilation allows newcomers to become 
part of the host society's collective identity which in turn provides economic, social, and psychological benefits. This involves presenting oneself in a way that is considered desirable and appropriate to people that hold the most power in society - in essence, White people. In a study conducted by Gilkinson and Sauvé (2012), recent immigrants to Canada (who immigrated less than ten years ago) were the least likely to identify with their community on a local scale, provincial scale, and national scale than earlier immigrants (who immigrated more than 10 years ago) and the Canadian-born. The authors suggest that structural barriers to integration, discrimination, and a lack of time to develop a substantial bond with one's community are the leading causes.

While all of the visible minority groups indicated experiencing some discrimination and racism in Canada, the Black population reported experiencing the highest number of racist incidents and the lowest sense of belonging to their province or region and to Canada on a national scale (Gilkinson \& Sauvé, 2012). Comparatively, the Black population had the highest rate of responding that they either "strongly agree" or "agree" that they identify as a member of their local community. It is unclear how large the authors consider a local community to be, so living situations that have a positive effect on identifying with a collective identity, such as institutional completeness and a relatively homogeneous racial community, are not accounted for (Ghosh, 2012). These community-building living situations certainly do not spread across the entire GTA, yet many people, including the participants of this study consider the GTA to be their local community. The extent to which my research participants identify with a collective GTA-wide community will be examined in this major research paper, thereby adding a more detailed dimension to existing studies. 
Anti-Black racism remains a huge problem in Canada and even in the most multicultural cities including Toronto and the GTA. A number of recent incidents of discrimination towards natural Black hair have been featured in the news media, thus confirming that Canadian society still generally conforms to Eurocentric standards of beauty and punishes those who refuse to conform to such standards. One incident occurring in 2016 involved a Black server employed at Jack Astor's who was instructed by her manager to take her natural hair out of its bun because company policy dictates that female staff must wear their hair down. When the server demonstrated to her manager that her natural hair could not fall flat, she was sent home for violating the company dress code (CBC News, Mar. 10, 2016). That same year, a bi-racial Black woman employed at Zara wore her hair in box braids gathered at the back and was told by both of her managers that her hairstyle did not match the "clean, professional look" of Zara (Lee-Shanok, Apr. 8, 2016). The managers then proceeded to try and "fix" the young woman's hair in the busy mall against her wishes, making her feel "humiliated", "upset", and "hurt" (Lee-Shanok, Apr. 8, 2016). Another incident occurred in June 2018 when a supply teacher employed by the Peel District School Board shared on Instagram a photo of a young Black student with braids next to a comical, gun-wielding, fictional male Black character who also wore braids with the caption, "Who rocked it better?? LOLOL" (Marychuk, Jun. 4, 2018). This selection of news stories of antiBlack racism in the Toronto GTA sheds some light on the reality that Canada is not the polite, inclusive, anti-racist country that many politicians would have citizens believe (Bell, 2016). Sociopolitical movements including the Natural Hair Movement and BLM are working to dismantle the current sociopolitical order that values Whiteness and penalizes Blackness.

While it is written in the Canadian Charter of Rights and Freedoms under Section 15(1) that, "Every individual is equal before and under the law and has the right to the equal protection 
and equal benefit of the law without discrimination and, in particular, without discrimination based on race, national or ethnic origin, colour, religion, sex, age or mental or physical disability," (Constitution Act, 1982). People of Colour are routinely treated unfairly and harmfully because of prejudices against their race. Furthermore, the federal Multiculturalism Act ('The Act'), “...for the preservation and enhancement of multiculturalism in Canada," has encouraged Canadian citizens and politicians to proclaim that Canada is one of the most diverse and inclusive countries in the world (Perry, 2015). While Canada's presence on the world stage and international commitments to undermining injustices like genocide, human trafficking, and racism suggests that Canada is a more welcoming country than others (and indeed it is), the idea that Canadians are welcoming to all races and cultural backgrounds is widely blown out of proportion. As discussed above, racism and discrimination plague the nation just like any other as is demonstrated by instances of prejudice against natural Black hair. In this study, I claim that Afrocentric or natural hairstyles worn by Black women are a marker of a cultural and/or racial identity covered under The Act. While racism, sexism, and other forms of inequality have declined since the inception of The Act in 1971, "there remains a deep divide between the ideology and practice of multiculturalism," (Perry, 2015). The practice of multiculturalism will be critiqued in light of participant opinions on its influence on the day-to-day lives of racial minorities in the Toronto GTA.

Rather that facing overt instances of racism, Black people in Canada are much more often subjected to covert, unassuming instances known as racial microaggressions as part of everyday interactions. Sue et al. (2007) have identified three distinct forms of microaggressions that occur in contemporary society: microassaults, microinsults, and microinvalidations. Microassaults are explicit, racially derogatory statements or actions with intent to harm the victim that take place within private spheres where the conveyor is spared from penalties. Microinsults are rude and 
insensitive statements that demean a person's racial identity and convey an underlying belief that the person of colour on the receiving end is inferior and lesser than (Torres, Driscoll, \& Burrow, 2010, p. 1076). For example, assuming a Black person in an affluent neighbourhood is engaging in criminal activity. Finally, microinvalidations are classified as "communications that exclude, negate, or nullify the psychological thoughts, feelings, or experiential reality of a person of color" (Sue et al., 2007, p. 274). For example, subscribing to the neoliberal idea of "colour-blindness" invalidates the experiential reality that Black individuals continue to battle with racism.

\section{Intersectionality and Critical Race Theory}

Sociopolitical movements such as Black Lives Matter and the Natural Hair Movement invoke a perspective on racial issues that are intersectional in nature and draw on the ideologies presented by Critical Race Theorists. Therefore, my research will be grounded within the two theories in order to understand the reasons behind, and the consequences of young Black women embracing their natural hair to make a political statement in the Toronto GTA.

It is well known that the guiding principles of BLM are centered on gender inclusive actions and are inherently intersectional (Austin et al., 2016; BlackLivesMatter.com, n.d. Dixson, 2018). Alicia Garza highlights the importance of acknowledging the work of Black women, trans folks, and queer folks within contemporary racial justice movements (Hall, 2016). Highlighting the lives of people who are multiply marginalized within contemporary Western society is the primary goal of the movement, thus channeling the work of intersectional feminist theorists such as Patricia Hill Collins and Kimberlé Crenshaw who argue that "a single-axis (e.g. race or gender) analysis is not only ineffective in capturing the experiences of Black women, but actually distorts their realities," (Hall, 2016, p. 91). Therefore, it is not enough to "recognize that 'Black Lives Matter'... they also matter intersectionally - as female, queer, trans, poor, and disproportionately 
segregated," (Hall, 2016, p. 92). By shifting the attention from the struggles that cisgender Black males face in contemporary Western society and instead widening the scope to take into account the specific injustices that all Black people face in light of the "interlocking systems of oppression" that Western Eurocentric society has imposed upon them (Lutz et al., 2011), BLM has become a "radically inclusive feminist movement, challenging the idea that resistance and freedom struggle should be rooted in only one issue area," (Hall, 2016, p. 95).

Since the theory's conception in the late $20^{\text {th }}$ century, there have been many off-shoots of intersectionality that seek to build upon what has already been established, or to focus more specifically on certain groups of people that face multiple layers of oppression. Additionally, intersectionality has been invoked by scholars across the humanities to add new perspectives onto other theories that have routinely excluded the experiences of people that do not fit within the preestablished mould. Intersectionality is a core tenant of Critical Race Theory (CRT) which takes an anti-racist perspective and "advocates for social justice for people who find themselves occupying positions on the margins [of society]," (Crichlow, 2015). Established in the mid-1970s, CRT was created as a new theory that could explore and analyse the complex relationship between race, racism, and American law (Delgado \& Stefancic, 1993). CRT theorists observe race as "a modern, socially constructed concept" and consider oppression and resistance as oppositional forces constantly at play in race and racism (Carney, 2016, p. 185). It is a tool used to "challenge the colour-blind notion of the law; the neutrality of law; subtle forms of racism; racial discrimination in law, as well as suggest how law can be used as a tool to challenge racism," (Crichlow, 2015).

The three main tenants of CRT are: (a) to recognize interest convergence - the White power structure will tolerate racial advances for Blacks only when they also benefit Whites (e.g. Affirmative Action policies that require companies to hire a minimum number of Black employees 
in order to appear more racially diverse); (b) reject colour-blindness and race neutrality that neoliberalism promotes; (c) refute and critique claims of meritocracy that sustain normative White supremacy (Crichlow, 2015). CRT considers the neoliberal policy of "colour-blindness" to be particularly problematic as it has given way to a new form of racism that turns a blind eye to the structural and systemic forces that perpetuate marginalization in contemporary Western society and wrongly blames the victims for the hardships they face (Carney, 2016). By positing that "all people are the same", colour-blind racism allows those who do not face racial oppression to believe that racism and institutional barriers are a thing of the past, thus dangerously providing a false sense of comfort and undermining the experiences of racialized people (Carney, 2016).

There is a significant activism component to CRT as theorists believe that "exposing the ways that racialized inequity manifests and persists must inform social actions that can lead to social change," (Dixson, 2018). The intersectional aspect of CRT has grown tremendously to account for all people who face multiple marginalizations in Western society, thus rendering both theories particularly useful in examining the social and political implications of natural Black hair in the multicultural society that is the Toronto GTA. The BLM movement is inherently intersectional as it recognizes the unique structural barriers that exist within an "intersectionality matrix" where "multiple systems of oppressions simultaneously corroborate and subjugate to conceal deliberate, marginalizing ideological maneuvers that define "Otherness." (Few, 2007, p. 454). Furthermore, BLM also relies on the use of personal narratives to understand individual contexts, an important aspect of CRT. For the purpose of my research, CRT and Intersectionality will allow me to uncover the personal narratives of research participants who face multiple, interlocking layers of oppression in the Toronto GTA. CRT will provide a lens that allows 
individual interpretations of activism to be explored, valued, and understood to challenge the hegemonic nature of Eurocentric society in Canada. 


\section{Chapter 3 - Methodology}

\section{Researcher Self-Disclosure}

I am a second-generation, mixed-race Black woman born and raised in the Greater Toronto Area, Canada. My undergraduate degree was completed at the University of Toronto where I majored in Diaspora and Transnational Studies, and completed a double minor in Caribbean Studies, and Sociology. My area of interest has always pertained to race and race-related issues including its social construction, and the various powers and limitations that are socially and structurally ascribed to particular races. As a mixed-race Black woman, I am able to identify with the participants of my study by acknowledging that Black people still face racism in Canada and occupy a lower position in the existing hierarchy of power compared to White people, particularly Anglo-Saxon Whites. Furthermore, like the participants of this study I have learned to embrace my natural hair despite the messages I received from some family members that straight hair looks more professional. However, I further acknowledge that my lighter complexion and my natural loosely curled hair has spared me from experiencing overt racism, and this fact may perhaps prevent me from completely identifying with the experiences of all of my interviewees.

I acknowledge my privilege of being able to attend post-secondary institutions where topics such as racism and Canada's multiculturalism policies can be openly critiqued and challenged. It was therefore imperative that I refrain from asking interview questions in such a way that conveys my own personal opinions or leads participants to answer a certain way. All things considered, I am aware of race/shade-based and gender-based prejudice due to my formal education thus far, as well as informal education I have received from family, friends, and peers who have experienced various degrees of racism and prejudice due to their darker complexion, their natural hair, and their

gender. I have benefitted from a rich informal education of the particular challenges faced by Black 
women in the GTA from family members who migrated to Toronto from the Caribbean during the 1970s and 1980s. As a result, there were no specific issues pertaining to my understanding and sympathizing with racism experienced by Black women who may have grown up in a different time than myself.

\section{Philosophical Worldview}

Since my philosophical worldview has largely been shaped by personal narratives and an understanding that the meaning of race is socially and historically constructed, my research is informed by Critical Race Theory (Crichlow, 2015; Delgado \& Stefancic, 1993) and framed within a Constructivist lens (Creswell, 2014). CRT and Constructivism emphasize the value of personal narratives and experiences as a legitimate source of knowledge and provide space for subjective truths to be explored. Furthermore, analyzing anti-Black racism is a core tenant of CRT and the inclusive nature of this theory allows individual understandings of racism, resistance, and activism to be accepted as valid, rather than compared and negated. Although the lived experiences of each

participant are unique, I explore a commonly shared phenomenon that is: all participants decided to embrace their natural hair while understanding that natural Black hair remains a politicized social issue in the Toronto GTA. I acknowledge the possibility that not all participants will outright claim that their choice to embrace their natural hair was politically motivated, which is why a broader description of activism was required. However, during sociopolitical movements that invoke Black pride, the number of Black women embracing their natural hair tends to increase (Austin, Oct. 21, 2014) and given my anti-racist lens developed from CRT, I understand that this choice always carries with it some political motivation that requires exploration. 


\section{Research Approach}

My study is based on qualitative research given the personal and multi-dimensional nature of my research question. This decision is also grounded in my desire to explore and understand the meaning individuals have ascribed to the social problem that is racism and the effect it has on their perceptions of multiculturalism (Creswell, 2014, Maxwell, 2009). I am instead in preserving the individualistic nature of responses in order to understand the multifaceted ways racism can change (or not) one's perceptions of how 'welcomed' their racial differences are within the community in which they reside. Therefore, a qualitative study that allows new theories to be generated based on participant responses that I, as the researcher, may not anticipate from the onset of my study was necessary (Maxwell, 2009). Rather than presenting a fixed set of variables to study (as in quantitative research), my study demanded room for other options to be explored as they were presented by participants.

\section{Research Strategy}

Because my study is an exploration of participants' individual understandings of what racism looks like in contexts that apply to their own experiences, my study is phenomenological. Rather than impose my own definitions and understandings of the various forms of racism onto participant experiences to determine if said experiences were racist as I understand it, my study provides space for various interpretations of racism to be explored. I, as the researcher, understand that every individual has their own outlook on reality that has been shaped by personal history that warrants academic attention (Levering, 2006). Therefore, it was imperative that I abandon my own preconceived understandings of racism and the deleterious effects it can have on those who experience it throughout the course of my study, which is a difficult thing to do given my formal education on this subject. 
The primary focus of my study is two-fold - (1) why Black women consider their natural hair an important symbol of activism, and (2) how, and if, racism directed towards their natural hair has influenced their opinions on the effectiveness of the Multiculturalism Act as a piece of legislation that seeks to preserve and enhance multiculturalism. I am also interested in the influence of sociopolitical movements such as Black Lives Matter and the Natural Hair Movement on the decision of participants to embrace their natural hair. Participants were asked about their opinions on these movements, but formal participation was not a necessary component for participating in this study. By exploring participants' accounts of racist events, I aim to contribute to existing research on the relationship between racism and feeling 'unwelcome' in one's community that typically involves new immigrants to Canada. Due to the individualistic nature of phenomenological research, however, it may not be possible to come to one consistent conclusion (i.e. that racism either does or does not influence opinions on the effectiveness of The Act). As the researcher, it will therefore be important to remain reflexive and employ my Intersectionality and CRT lenses throughout the course of my study to identify similarities between varied experiences and opinions. The 'reality' I will be exploring is not an objective 'reality' that will apply universally to all of my participants. Each participant will present their own subjective 'reality' upon which I will base trends or themes that emerge.

\section{Interview Sample}

My sample consists of six Black (and mixed-race/bi-racial) women between the ages of 21 and $65+$. The inclusion criteria for participants in this study were that they (a) self-identify as Black/mixed-race/bi-racial; (b) self-identify as a woman (this includes transwomen); (c) are at least 18 years old; (d) live in the Toronto GTA, and (e) decided to stop chemically or thermally straightening their hair, or stop wearing full-coverage wigs and weaves as a form of activism while 
understanding that natural Black hair remains a sociopolitical issue in the GTA. Using a broad and inclusive understanding of activism was necessary since I wanted to include women who may not have made the conscious decision to wear their hair natural specifically to make a political statement. A broader understanding of activism allows participants to explain what activism looks like to them and they are not confined to my own definition and understanding. While formal or active participation in a social movement such as the Black Lives Matter movement or the Natural Hair Movement was not a necessary criterion for participating in this study, all of the women were asked about their opinions on such movements and if their hair decisions were influenced by any related social movement, in the past or present. The women that participated vary considerably in age, educational backgrounds, professions, and income levels which suggests that issues pertaining to natural Black hair transcends generational and class boundaries.

\section{Recruitment Process}

The sample strategies used for this research was a combination of purposeful sampling and snowball sampling (Marshall, 1996). A recruitment letter that explained the purpose of the study, inclusion criteria, and what participants could expect from the interview process (Appendix A) was sent to four potential participants that I believed satisfied the inclusion criteria. Of those four, two agreed to participate while the other two clarified that they did not satisfy the inclusion criteria but knew other women that might. All four women were asked to identify one or two other women that they believed satisfied the inclusion criteria. A total of six women were identified through the snowball sampling process. All six were sent the same recruitment letter and five women satisfied the inclusion criteria and indicated their interest in participating. Based on the limited time I had to complete this study, my sample size of six women had to remain firm. The last woman to contact me was thanked for her interest in participating and advised that the study was full. Throughout 
the recruitment process, the importance of freely-given consent to participate was emphasized and participants were assured that participation was non-obligatory and would not affect their relationship with me, those who recommended them, or Ryerson University. The six women who agreed to participate were sent an electronic copy of a consent agreement (Appendix B), were asked to review it carefully, and to ask any questions they had about the study and/or the nature of their involvement. Two physical copies of the consent agreement were brought to each interview and were reviewed and signed by each participant prior to the interview. One signed copy was given to the participant, and one was kept for my records.

I decided not to offer financial incentives but as a courtesy, participants were offered a beverage (such as coffee, tea, or juice) to enjoy during the interview process. I also offered reimbursement for any travel costs to and from the interview location (i.e. TTC tokens or associated parking fees). Prior to the interview, participants were told that they reserve the right and are encouraged to review their audio and written transcripts and will be able to make any edits to their responses. Participants were also told that they could receive a final copy of the study so they can see the value their participation brought to my research. Due to the sensitive and potentially traumatic nature of some of the questions asked, however, I ensured that all participants understood that acceptance of these texts was optional and non-obligatory.

\section{Data Collection}

Prior to the interviews, participants were given a demographic questionnaire (Appendix C) that asked about their racial identity, gender identity, age, citizenship status, level of education, current profession (student was included as a possible profession), and current annual income range. These questions were included to provide contextual information about the participants to see if issues pertaining to natural Black hair transcended generational and class boundaries among 
participants. Participants were given the option to skip the question about citizenship due to its potentially sensitive nature and the risk that they may be identified by immigration officials if they indicated an "illegalized" status (Bauder, 2016). None of the participants indicated such a status. Participants were also advised that they would be identified throughout the study by a pseudonym in order to protect their identity and ensure confidentiality. Rather than assigning pseudonyms, participants were given agency to choose their own. Inspired by Gillespie's (2013) work and interview procedure, participants were asked, "What word or phrase best describes your hair's identity?" The answer to this question became the pseudonym which is used to identify each participant throughout the study.

Interviews lasted between 50 and 120 minutes each and were semi-structured in order to encourage participants to openly discuss their personal experiences and choices in response to guided open-ended questions that presented the topics of interest. Because racism and activism can be portrayed in any number of ways and will carry different meanings and significance to participants, my interview style had to be flexible and provide space for participants to explore what these terms mean and look like to them. My primary data collection tools were an interview guide with questions asked to each participant (Appendix D), as well as a note pad to write down key words or phrases said by participants that warranted further exploration. Due to the openended nature of the interviews, supplementary questions arose naturally and were not included in the interview guide.

To increase the 'trustworthiness' of my data collection methods, all interviews were audiorecorded and written transcripts were produced. It was crucial that I remained open-minded and reflexive to participant data, using all relevant information provided by participants rather than excluding any data that did not conform to identified themes. Excluding such data would have 
threatened the validity of my study (Guba and Lincoln, 2003). To remain as reflexive as possible, I have acknowledged my own personal worldview, biases, opinions, privileges, and experiences and have removed them as much as possible from my interpretations of the data. Because data collected in qualitative studies is so complex, I provide "thick descriptions" of my data (i.e. include very detailed descriptions of what racism and activism looks like to each participant and how it has affected them individually) and allow readers to come to their own conclusions about the data, rather than tell them what conclusions they should make (Tracy, 2010).

\section{Data Organization, Analysis, and Interpretation}

To ensure the names of participants remained confidential, a typed document of participant names and their assigned pseudonyms was stored on a password-protected external hard drive. To analyze my data, I critically engaged with the transcripts and wrote down themes or key words that were referenced by all participants. While each participant was advised before the interview that they may be asked to meet with me again so that I may perform 'member checks' to ensure that the themes that emerged properly represented the information they provided, this was not necessary since each participant gave clear answers to all of the interview questions. Due to the nature of a phenomenological study that values personal, subjective 'realities', I did not need to change my research design if/when I encountered discrepant data. The inclusion of all relevant data in my analysis and interpretation and simply "letting the text talk" rather than inputting meaning that is not there is how I ensured my research remained dependable (Graneheim and Lundman, 2004, p. 111). My interpretations of the data only apply to the participants of my study because the extent to which my data is generalizable to other populations is currently unknown. 


\section{Chapter 4 - Results}

For this study, six Black/mixed-race women were interviewed. The following section presents their demographic information and their responses to the interview questions. Participants were asked about what they learned about the natural hair textures of Black women, how these textures are perceived in the GTA, if natural hair is an important form of activism, and if they were currently involved in any sociopolitical movements. They were then asked to define 'racism' in the context of the GTA and provide examples of any blatant or covert racism they have faced directed towards their race and/or their hair, specifically. In the final section, participants were asked if Canada's Multiculturalism Act affects the day-to-day lives of racial minorities, and to define 'social inclusion'. They were also asked if there is any obligation to make people feel welcomed in society, and if cultural celebrations can facilitate a sense of belonging. To avoid assigning Eurocentric pseudonyms that are typical of qualitative studies in North America, pseudonyms were chosen by the participants using their responses to the question, "in a word or a short phrase, how do you define your hair's identity?" When describing their own hair textures, some participants referred to the Andre Walker hair typing system that measures curl pattern on a scale from 1 (straight) to 4 (kinky) with three sub-categories within (A, B, and C) (Walker, n.d.). Any information that may have compromised their anonymity (i.e. the names of schools or workplaces) has been omitted.

\section{Explosive}

When asked about her hair's identity, Explosive indicated that that was the first word that came to mind. Explosive is a 24-year-old Black woman with a Bachelor of Arts degree. She works as a Speech and Behaviour Therapist and earns between $\$ 21,000$ and $\$ 40,000$ annually. Explosive defined her hair texture as $4 \mathrm{C}$ textured hair - very tight coils and the curl pattern is difficult to see. 
She further defined her hair as "afro-like and big." At the time of the interview, she wore her hair in Crotchet Dreadlocks. She indicated that since she has gone natural, she never styles her hair in a way that would not be considered natural.

Explosive defines natural hair as "hair that hasn't been altered with any chemicals... hair that's sort of just left to do its own thing." When asked about the messages she received about kinky hair versus straight hair while growing up, Explosive indicated that she would often hear from friends or acquaintances that straight hair looks neater than afro hair. The messages conveyed to her were that afro hair “couldn't just be left the way it was. You had to either straighten it or hide it under braids, or a wig, or a weave, or whatever." Explosive explained that $4 \mathrm{C}$ hair is usually described as "nappy" which is a derogatory term. Compared to other hair textures in the 2 and 3 range, category 4 hair is "looked down upon" and is seen as "messier and unkempt". Explosive indicated that these prejudices are deeply entrenched within the mentalities of particularly older Black women, and common even within the natural hair community worldwide.

Explosive used to perm her hair straight and wear weaves until about 2014. She stopped getting perms because it would irritate her scalp and she learned more about the damage it does to one's hair. She indicated that she initially found it difficult to manager her hair and "make it look presentable to people in society" but online research and YouTube video tutorials taught her how to take care of her hair and how to style it. When asked why it is important that she wear her hair naturally, Explosive explained that trying to adhere to society's standards was hurting her hair and risking her health. She also highlighted the importance of self-love as a personal tool to combat criticism and being "pushed aside" or marginalized in society, which affects one's perceptions of self-worth. 
When asked about the comments she has received about her own hair, Explosive indicated that she has never received blatantly negative comments, but family members have drawn attention to her hair in a negative manner when the style has "grown out." Some of the comments she has received are, “don't you think it's time to do your hair? When are you going to do something with your hair? Or, you can't take that to an interview, you know, you need to do something with it." These comments made her feel self-conscious about wearing her natural hair rather than keeping it in braids and made her question at times if she should continue to wear her hair naturally. Although Explosive has never received negative comments towards her hair from co-workers, managers, or bosses, she noticed that she will only receive compliments when her hair is freshly braided or styled, rather than when she wears her hair naturally in an afro. She further indicated that she only rarely has adults try to touch her hair without her consent but encounters it much more from the children she works with due to their curiosity.

When asked if she considers her natural hair to be a political statement or a form of activism, Explosive recounted that although she went natural for the health of her hair, the comments she would receive from family members regarding the need to do her hair ended up fueling a desire to continue being natural:

"...the more comments I heard, the more I wanted to remain natural to sort of show them that I don't have to wear straight weaves or do something to my hair in order to look presentable. I can be presentable with my natural hair as well. So, it didn't start as anything political or anything like that, but I feel like as time went on, it sort of became one, like a political thing."

Explosive considers natural hair to be an important form of activism because:

"I feel as though it speaks for itself when people see my natural hair because a lot of Black women keep their hair hidden under wigs and weaves or straightened or permed and when people see my hair as wild as it is and as crazy as it looks, it sort of reminds them that I am Black... I feel as though a lot of people don't want to be reminded of that. I don't speak like a stereotypical Black person, I don't quote-unquote act, I've been told, like a 
stereotypical Black person so oftentimes people sort of, other than my skin colour, people sort of forget that I am Black and my hair is sort of an in-your-face reminder of that and um, a lot of people don't like that."

Explosive explained that her natural hair seems to make older Black women more uncomfortable than non-Black people due to intergenerational knowledge about the undesirability of natural Black hair being passed down from those who grew up experiencing blatant racism towards their bodies and by extension, their hair. "I feel as though they've been told for so long that their natural hair isn't beautiful, or their natural hair is messy or unkempt, so they pass that on to the younger generation.” This perception ties into Explosive's belief that self-love within Black women is, in itself, an important form of activism because it represents a resistance to societal norms that marginalize Black bodies and deem natural Black hair as undesirable.

Explosive could not recall ever experiencing blatant racism but has strong memories of microaggressions she has faced. When she first moved from Scarborough to the Richmond Hill/Markham area as a teenager, she noted the difference in the racial makeup of her community and felt like an outsider due to a lack of visible Black people. She recalled receiving unnerving looks from strangers while in public places such as grocery stores, which she believed was due to her race. When asked if she still receives these looks in public places, Explosive explained that she does not, but it may be that she just does not notice it anymore. When asked to recount one instance of racism that stands out in her mind, Explosive discussed a past friend who frequently expressed surprise when Explosive received good grades in school:

"I had this one acquaintance, friend I guess, who always made comments about the way I speak and like, my marks in school and things like that, and they would always approach me in shock and surprise like, 'oh I can't believe', you know, and you can tell that they're surprised because of my race and because I'm Black, so I feel like that was pretty racist, that because you're Black you can't be smart, or because you're Black you can't speak well, or because you're Black you can't do this, so I tried to correct them multiple times but I don't think it made any difference to them. They continued in their ignorant ways." 
Explosive explained to the individual that her race has nothing to do with her good grades in school or the way that she spoke, to which the individual claimed that they "were only joking". Explosive often corrects people when they make inappropriate comments directed towards a particular race in order to educate them and to prevent them from offending someone who may react in a violent or aggressive manner. While she does not consider it to be a personal obligation, she believes that it is an individual duty to try to make everyone feel welcomed in a society, especially in Canada that is presented as "a place of diversity and a place of welcoming different groups." She further explained that "if the government makes rules and regulations, if the people aren't following it, and there's still, you know, racism and discrimination, then it doesn't really make a difference."

When asked about what racism looks like in the Canadian context, Explosive defined it as "intolerance to any race that's not your race". She believes that not all individuals know when they are making racist or offensive comments, therefore attributing a lot of negative comments to ignorance. She indicated that she has never experienced blatant racism in the GTA and considers herself "lucky" as a result. When asked if racism is a problem in the GTA, Explosive responded:

"I'm sure it is. I've never experienced blatant racism yet, who knows what will happen in the future, but thus far I haven't. But I'm sure if you speak to multiple other people they'll tell you of instances where they've experienced it but, so yeah, I'm sure it is. Racism is everywhere unfortunately..."

She further elaborated that racism is not only expressed across racial boundaries but exists within racial groups as well which affects how groups are perceived by racial outsiders. "We need to be solid as a group first before we can expect people outside of our race to welcome us, or to see us as anything worthwhile. We need to talk about the intolerance that's going on even within our own community before we expect anybody else to tolerate us outside of our community." To 
achieve this, Explosive underscored the importance of representation in the media of darker skin tones and kinkier hair.

When asked if the Multiculturalism Act affects the lives of racial minorities, Explosive explained,

"I feel as though it [diversity] is celebrated but just because it's written, or it's said that diversity is welcomed, or we celebrate diversity doesn't mean there isn't still discrimination or racism happening... We encourage people from all over to come to Canada and feel welcome in Canada, but I find that a lot of people tend to gravitate towards people that are like them, so you're still gonna find communities where, you know, people of the same race sort of cling together and there isn't room for somebody from another race to sort of break into that..."

Explosive also believes that "it's sort of silently agreed upon that people with Eurocentric features or people who are of the majority rather than the minority are sort of welcomed more than people who are part of the minority community." She attributes this to "fear" of unfamiliar cultures, resulting in minorities being "pushed aside or marginalized because they're different," thus demonstrating an "undertone of racism." She recalls in elementary school the darker-skinned children being teased and made fun of by those who were lighter-skinned.

To Explosive, social inclusion means, "to be a part of a group...[and] for a particular group to be included in society." She considers it important that people feel welcomed in society in order to maintain peace. She explained that when people live in fear, and fear can be caused by what people do not know or understand about others, people "begin to act in hostility and act violently." She posits that cultural celebrations such as Caribana, Afro-Fest, Taste of the Danforth, etc., and genuine attempts to understand other cultures can reduce segregation and promote feelings of inclusion. When asked about her own sense of belonging and identification with any groups in the GTA, Explosive said that she identifies with Christian religious groups and the Nigerian community more than the general Black community. She went on to say: 
"I just feel more free around them [Nigerians] because they are like me, and I can be myself around them because my family is Nigerian... Even though I am Black, I feel as though when I'm around the general Black population, I'm pressured, and I don't fall into the pressure, but I feel as though there's an unsaid rule that I need to act like them, and I need to act like the stereotype of a Black person and I just can't, I don't know how to do that, and so, it just makes me feel uncomfortable. But when I'm around Nigerians, even though I've been told that I'm not as Nigerian as I should be, it's more of like, there's no pressure to be the stereotypical Nigerian, or to have the accent, or to have whatever, they just welcome you, like if they know you're Nigerian, you know, you're seen as Nigerian no matter what so, that pressure is lifted when I'm around Nigerians."

Although Explosive is not affiliated with any sociopolitical movements in the GTA, she is aware of the work that Black Lives Matter (BLM) and the Natural Hair Movement is doing to improve the lives of Black people in North America. When asked about the intent of BLM, she explained that her perspective on the movement has shifted over time. Her initial understanding of the movement was "to sort of highlight the fact that Black people are people too, and that their lives aren't meant to be destroyed so easily by, you know, cops or whoever, that we are just as important as White people, Asians, and other races and our lives matter as well." The goal of the movement became unclear to Explosive over time, however, as the media has "caused it to appear as this, you know, radical, violent type of movement... I'm not really sure what's going on." Explosive indicated that she is unsure if the media is purposefully presenting BLM as a violent movement, or if the goals of the movement have shifted.

\section{Freeing}

Freeing is a $65+$ year old Black woman with a post-graduate doctorate degree $(\mathrm{PhD})$ in Adult Education and Women's Studies. She currently works as a Professor and earns $\$ 81,000+$ annually. She described her hair texture as "a mixture of some strands that are straight and some strands that are kinky and some strands that have a mind of their own." At the time of the interview, 
she wore her hair in Sister Locks, or Sister Dreadlocks. She indicated that since she has gone natural, she never styles her hair in a way that would not be considered natural.

She defines natural hair as "hair that's just yours, it doesn't have any chemicals in it." The messages she received while growing up about straight hair and kinky hair came primarily from her mother who used to style Freeing's hair as a child and would wash it with alcohol in an attempt to straighten the hair texture. She grew to learn that her hair was "bad" and it "needed to be straight" to be considered "good hair." She recalled feeling jealous of her mother's long, straighter hair and thinking to herself, "why can’t I have long hair like hers?" She believes that her mother's use of alcohol on her hair stemmed from "her inability to accept that she had an offspring with hair like mine." Freeing recalled going to hairdressers at a young age to have her hair straightened with hot combs, which she described as an "awful experience". One experience when she was about 10 years old left her with a physical scar due to the hairdresser accidentally dropping the hot comb on her arm. Once chemical perms became more popular, Freeing referred to getting her first perm as a "coming of age" ritual. She recalled it as a "horrific experience" and talked about the intense burning sensation on her scalp. Freeing referred to "the pressure that people are under to maintain a certain image" as a reason women are unlikely to wear their hair naturally, "especially if it doesn't look straight, if it doesn't conform to the image of the dominant culture, which is straight and usually blonde. I think a lot of women feel that they must alter their hair in order to fit into that mold and to get ahead."

Freeing went through periods when she would stop perming her hair for some time. She recalls while in University getting her undergraduate degree, she was exposed to new literature and an environment in which Black issues could be openly discussed, thus aiding her rediscovery of what it meant to be a Black woman in Canada. With this knowledge, Freeing "began to realize 
that I didn't need to be perming my hair anymore, so I stopped." She wore her hair in a big afro style and recalled going home a number of times and her mother would say, "I've ruined my hair, look what I've done to my hair, that's not my hair, and all of those kinds of things." After she graduated, she traveled to Bermuda, her country of origin, and began perming her hair straight once more. She received messages from hairdressers like "the perm looked good because the afro, you know, that's all bad hair." During the early 1980s when she returned to Toronto, Freeing embraced her natural texture once more, switching between the popular style of the Jheri Curl and her natural afro until the late 1980s when she began perming her hair again. Freeing then regularly permed her hair straight until 2002 when she was diagnosed with fibromyalgia, a common and chronic syndrome that causes bodily pain and mental distress. She attributed the harsh chemicals in the perm to its onset and began to focus on her overall health, beginning with wearing her hair naturally. She also lost a lot of hair due to years of perming. At first, she wore it in an afro but found it difficult to manage, and in 2006 switched to the Sister Locks she currently wears. She considers the Sister Locks to be "freeing" because "I don't have to worry about doing anything with it. I also know that it's me." Although the Sister Locks allow her to be herself, Freeing indicated that she would not have worn that style prior to her mother's death in 2000 because "when I had my hair permed, she felt better." Freeing made it clear that straightening her hair was to please others, while wearing it natural pleases herself.

When asked her opinion on how the natural hair textures of Black women are perceived in Canadian and GTA society, Freeing explained that they seem to be better received in academic settings as she has witnessed many of her colleagues wearing their hair naturally and never receiving any criticism for it. She compared the climate of tolerance of the academic sector to the less-than-tolerant private sector by citing "Black on Bay Street", an article featured in The Globe 
and Mail in 2017 in which a Black female University of Toronto Law graduate recounted her struggle to fit in and be accepted in a number of law firms on Bay Street in Toronto. Although she sees more women wearing their hair naturally in recent years, she has not seen many of them "move up the ladder in terms of becoming a Chair or a Dean." She went on to say, "I mean it [natural hair] is accepted but it's not as accepted as it should be because you still find that some people are not able to move up the ranks as maybe they should because they wear their hair natural."

While Freeing does not consider her decision to embrace her natural hair a form of activism, she does see it as a "small 'p' political" ideal because she is "comfortable being who I am." She does, however, consider natural Black hair to be an important form of activism because, “it says you're being who you are and you're not succumbing to societal pressure of making yourself to be something that you're not." When asked if wearing natural hair is a necessary component of being "unapologetically Black", a sentiment expressed by BLM, Freeing stated,

"I think so, if you want to look at it that way... I feel like if one is going to one of those protests with your hair all nicely permed, nice and straight, you've got all these nice straight extensions, to me, from where I sit, I don't know if that's really being true to the movement so why go? I don't know, it feels somewhat hypocritical... Like on the one hand, you're saying, 'I'm here', but on the other hand you're saying, 'This is how I present myself, I don't feel proud of who I am and I'm not going to be my natural self, I'm just going to be this presence that has this straight hair'."

Freeing has never experienced blatant racism towards her hair but has considered prejudice to be a factor when failing to attain jobs after successful interviews. She is also careful with her teaching methods to not appear as "an angry Black woman" when discussing identity and inequality in the classroom. Freeing understands racism in the Canadian context to be "insidious, it's definitely come out of social construction of the notion of race, and what I see in Toronto is that it's very subtle and very insidious." She explained that the language the media uses to describe 
a Black person who has committed a crime like "monster, beast, and criminal" is not used when describing a non-Person of Colour. People make "subtle comments" directed towards people that "don't kind of fit the norm, because they don't fit the image of the dominant culture." She recalled watching a documentary that revealed the increase of hate groups in the US since Donald Trump's election as President and believes "there's almost like a license for people who had those tendencies to come out and be even more vocal about their dislike of people who don't look like that."

Freeing believes that many racist comments are borne out of ignorance and although "we're all racist in some way, shape or form, because we all have this fear of somebody who doesn't look like us," sometimes "people don't even realize that what they're saying is racist." When asked if she has ever had a student express a racist sentiment in class, Freeing explained that while it has never been overt, sometimes she has sensed a hint of prejudice and will then incorporate it into the lesson plan as a teaching moment. She does not outright correct people when they have made a racist comment in her presence but expressed that she "should." Although Freeing has not experienced blatant racism since she has embraced her natural hair, she recounted a few microaggressions in which her identity, qualifications, and experiences were "negated." One instance occurred before her $\mathrm{PhD}$ graduation ceremony when "the woman started heading towards the rack where the regular gowns were, and she came back and said, 'Which degree?' I said, 'To begin with, you didn't ask me whether its $\mathrm{PhD}$, Masters, or BA.' I said, 'it's PhD.' 'Oh, I'm so sorry!' (she said). So, there was that assumption that I couldn't possibly be getting a PhD gown, so she went to the other gowns." Another incident took place after she became a Professor. "I had booked a video, and I went to collect the video at the library and the young person behind the desk said, 'Well, you have to tell your Professor to come collect it.' I said, 'I am the Professor.' 'Oh, 
I'm sorry,' (he replied)." Freeing recalled trading such stories with some of her colleagues who are also People of Colour.

When asked if racism is a problem in the GTA, Freeing said, "Yes, unfortunately." She explained that it affects all People of Colour and Indigenous People, and is present in the language used to describe and discuss these groups of people who are mistreated as a result of prejudice. Freeing was familiar with Canada's Multiculturalism Act which she believes “doesn't do anything! It's just that, it's a policy, it's something that sounds nice, looks nice but in reality, it doesn't mean anything." She further explained,

"I really feel that multiculturalism is more policy than reality, it's not a lived kind of thing, and I don't know that having the many different segments in the city that we have is beneficial to this whole notion of us getting along because if I go on the street to North York, it's a heavy Iranian population, if I go a little further West to Bathurst area, its heavily somewhat Russian and somewhat Jewish, if I go to another area I see a lot of Italians, if I go to the East end I see a lot of Blacks, if I go to the sort of middle, downtown West, I see Somalians. So, I know it's a comfort issue, but it's also segregating in some ways and I don't think that it's really a blending of cultures from a multicultural standpoint."

Freeing considers the natural segregation of communities to be "one of the disadvantages of the multiculturalism policy that we have." She has witnessed the negative results first hand while grading students' work:

"I do a lot of group work, [and] they tend to form groups of their ethnic group and sometimes that's not necessarily beneficial because when I get their papers for example, I have challenges reading it because the English that they're using is a stilted form of English that came from someone who is not teaching them the English that we speak everyday but instead, they're teaching them an English where they're using vocabulary that is not part of our everyday vernacular."

While Freeing believes that racial segregation is a negative consequence of The Act, it can positively affect one's sense of comfort in a community, which can help people feel welcomed. When asked how she understands the term social inclusion, Freeing indicated that she was not familiar with the term but believed "it's how one feels included in various aspects of society in the 
workplace, in social settings, in the media, I guess that's probably how I might take it." Certain spaces do feel more welcoming to Freeing than others, but this is influenced by culture and relatability, rather than race. For example, even though Freeing is from Bermuda, she often does not identify with other Caribbean folks because there are cultural differences between Bermuda and the West Indies that she does not relate to. She explained that she feels the most comfortable around her colleagues in the education sector because she can relate to them the most. When asked if she has ever felt uncomfortable in a public space, Freeing noted that occasionally she will receive unnerving looks from people of other racial groups in malls and grocery stores near her place of residence, where she is a minority as a Black person. That being said, her attendance of these spaces is not affected. Freeing believes that there is an obligation to make people feel welcomed in society, but the extent to which this obligation is realized differs between groups of people. While The Act seeks to make everyone feel a part of the Canadian community, "it doesn't quite work [because] with some individuals, they're made to feel welcomed and with others, no... it depends on the body that individual is in." Freeing considers cultural celebrations like Caribana, Afro-Fest, and Taste of the Danforth a possible way to facilitate a sense of belonging and community in the GTA, but they do little to "help in terms of building something that's more longterm." Instead, representation in different spaces, such as government and the media, plays a more important role in fostering a "positive identity and sense of self."

\section{Defiant}

When asked to define her hair's identity, Defiant indicated that it is reflective of her own identity in that is it "unapologetic, quick, forceful, very independent, and defiant." Of those words, she preferred "defiant." Defiant is a 26-year-old mixed-race Black woman currently working towards a Bachelor of Arts degree. She is employed part-time as an Equity Advocate and earns 
less than $\$ 20,000$ annually. She described her natural hair texture as $3 \mathrm{C} / 4 \mathrm{~A}$ and at the time of the interview had it "closely shaved on the sides with curls on top that are a few inches long." She also described it as "thick" and attributed the texture to her Nigerian and Latin American heritage. Defiant indicated that since she has gone natural, she never styles her hair in a way that would not be considered natural.

Defiant defines natural hair as "How it grows out of your scalp I guess, like natural to me is what you've been given and what you own and what comes to you naturally um, without manipulation like chemical manipulation or permanent manipulation or even consistent manipulation I would say, like if you're constantly straightening your hair, in my opinion that's not your natural hair either." Growing up, Defiant received messages from her Latin American family that "straight hair was the only thing that was acceptable" and was required to look "presentable", "pretty, and to "fit in". Her hair was chemically permed straight from a very young age because "they just didn’t know how to deal with my hair without a relaxer." By growing up in a predominately White neighbourhood, Defiant learned that "it was just too Black to wear your curly hair, [and] it was a lot harder to fit in." Furthermore, wearing her hair straight provided an "element of safety" against the targeting and bullying she endured as a Black queer person. She embraced her natural hair at the age of 15 or 16 out of the frustration of constantly straightening her hair due to sweating it out from playing sports. The regular heat manipulation began to cause hair loss so Defiant decided to embrace her curls and learn how to care for them by watching YouTube video tutorials, asking Black friends with natural hair, and visiting salons that specialize in Black hair textures.

Defiant's natural hair is integral to her identity and her work as an Equity Advocate. Her decision to go natural was influenced by learning about her ancestry and "deciding to get woke" 
on issues of anti-Blackness. She believed that straightening her hair presented her as "a 'good negro', or like a conforming Black person," which left her feeling untrue to her identity. Defiant battled with clinical depression as a result of the bullying she endured while growing up and "realized that the more I love myself, the freer I feel and happier I feel in my freest form, which is natural." She considers going natural a "reclamation" of one's identity and a crucial part of the self-decolonizing process. The Black Panther Movement and Angela Davis were important figures in her own development through empowerment and creating a sense of community in which Defiant's natural hair could be accepted and celebrated. Because of her work and passion for activism, communal accountability, and the denouncing of "violent forms of body subjectivity that we experience as Black people," Defiant considers her natural hair to be a necessary element of her being and would feel hypocritical if she "practiced one thing internally and not practice it externally." She referenced the theory of intersectionality and said, "wholeness [is] important in order to feel in alignment," and her natural hair "aligns with who I am at my core with the values that I've assigned to myself and with what genuinely sits right or feels right with my spiritual side." When asked if she considers her decision to embrace her natural hair a form of activism, Defiant explained,

"It is, absolutely it is. As much as I say my body is not a political playground, my body and how I take up space and how I'm perceived impacts what I receive from people around me and changing my natural hair has changed the amount of interest that Black men might show in me when wanting to date, changing from a curl to a 'fro [afro] tends to get me or has got me less support, or people take me less seriously in like, professional settings and comments are different too... I might be told I'm pretty if I look one way, if I did my washand-go and eco style it and get like, a good chunk of gel in there so that the curls are defined for most of the day... I'll get a 'you look so nice today', but I won't get the same sort of feedback for 'froing my hair or leaving it in my twist-out or in some type of really easy head tie where there's nothing else coming out 'cause I didn't want to do my hair that day... So yes, resistance is in the existence of natural hair." 
She considers natural hair to be an important form of activism because "it's visible and tangible, and it's important for shifting representation." While she indicated that she does see some improvements in the way that natural Black hair is perceived in the GTA, "racism is ever present and anti-Blackness is very real and it absolutely includes hair." Defiant shared some examples of racism she has faced in the GTA. She was fired from a retail job for wearing her hair in an afro, she was told by another employer that her hair looked like "slave hair" when it was styled in single braids, and she was denied an opportunity to participate in a photo shoot because her hair "didn't go with their brand, which definitely meant it wasn't straight." When asked if she ever felt ashamed or self-conscious about her hair based on these negative experiences, Defiant said, "Yeah, all the time," and explained that being denied the opportunity to provide labour because of her natural aesthetic "has an impact on your worthiness," and many times, she has denounced her natural hair in an attempt to minimize the harm inflicted upon her. She has also experienced more subtle forms of racism such as unwanted touching of her hair, being denied the same pleasantries that White customers were given in places of business, White women expressing unease with leaving their belongings unlocked in a spa while Defiant was there, and has been made to feel self-conscious by family members who are lighter-skinned with straighter hair textures. Family members would tell her to straighten her hair because it looked "prettier" and "more acceptable". She recalled her mother preventing her from wearing her hair in Bantu Knots, an Afrocentric style, to an event and instead forced Defiant to pull it back in a tight bun that hid her curls. Even at the time of the interview, Defiant said her family still draws negative attention to her natural hair but rather than focusing on its texture, now they are focused on its length. "They don't want me wearing my hair in queer fashion styles. I think they'd be fine with it if I wore my curls these days, they just want it to look ultra-feminine.” 
When asked how she typically reacts to negative comments from her family members, Defiant blatantly said,

“Fuck you! (laughs) It's a big 'fuck you' from me. I'm way past the point of trying to rationalize other peoples' hatred and internalize anti-Blackness. I'm done having the conversations or doing their emotional labour to try and convince them of what is correct, quote-unquote, and what isn't. This is what feels good to me, this is how I like it, and I do what I like."

When asked to define racism in the Canadian context, Defiant offered the following view:

"Well, there's a myth of multiculturalism that likes to float around the air in Toronto and Canada in general, this idea that we're some inclusive and forging and melting pot sort of city or nation, which is entirely a lie. The insidiousness of racism is absolutely systemic, top to bottom. Until we acknowledge Indigenous genocide, then we really can't acknowledge anything else, but the way Black people are treated here is gross and continues to be gross. There were slaves in Canada, the wealth in Canada comes from slave money and colonialism. The way that we're not allowed to have the same access and privilege is prominent, and so I guess I would define Toronto's racism... in systemic oppression and also in microaggressions in the way we treat each other, from a person to person basis."

Defiant believes that people do not always know when they are making racist comments and attributes it to "ignorance [and] insidiousness for the most part, [but] ignorance to me is not an excuse either because information is readily accessible." She posited that, "we've been conditioned to be lazy in sourcing that information as privileged people when it comes to Blackness because supposedly, there's an idea that Blackness isn't worthy of it." When it comes to unwanted physical contact of her hair, Defiant claims, "I don't think it's always intended to be a violation of my body and my privacy, I don't think [they're] acknowledging that there's a lack of consent involved, but that's because [they've] internalized anti-Blackness to such a degree that it's just not a second thought." When asked how she usually responds to strangers touching her hair, Defiant explained, “there's been a few times where people have tried to put their hands in my hair and I scream rape." As a survivor of sexual assault, Defiant "[doesn't] fuck around with the lack of consent." She experiences these kinds of instances often and has noticed a difference in the 
typical reactions she will get from people. White women "tend to recoil quickly" but her nonBlack friends will ask her to explain her perspective further "and do their emotional labour for them," which she has "no time" or "emotional space" for.

Defiant considers racism to be a "huge" problem in the GTA:

"There's not one person that I know in a Black body who hasn't dealt with anti-Blackness growing up in Toronto or visiting Toronto... it exists in our experiences, it exists in every moment of every day, it exists in the classrooms that I'm in where the science I'm learning has been experimented on Black bodies without their consent. These learnings literally come from the backs of our ancestors like, or at the expense of our ancestors in the fact that everything is regimented or created as an extension of a colonialist system and imperialist system that is built on slavery..."

Furthermore, she does not see how the Multiculturalism Act affects the lives of racial minorities and while, "it's great to theorize... if it doesn't impact my physical existence and my every day existence, then like, what have you done for me?" She acknowledges some benefit to The Act of "opening up conversations about multiculturalism" but considers this a small win because, "even when people hear the conversation, they're still not willing to sacrifice their privilege in a lot of ways so we're still stuck in the same positions." Conversations are not enough, "but it's a start." She does not believe that cultural celebrations facilitate inclusion or adequately educate cultural outsiders because, "it's not accessible to everyone." Caribana, for instance, "can be really positive to help like, combat the idea of angry Black people, lazy Black people, or whatever, I think that can be helpful in some ways to humanize us, I guess, in the media." However, "It's one thing to allow us to be able to dance in minimal attire on one road closure that's highly policed, that costs a lot of money and that's gated off to the majority of the community so you can't even really socialize with one another, and there's also a really awful classist thing about it, like accessing a costume to play mass starts at like $\$ 300$, so it's not available to everyone, and there are no accessibility accommodations if you can't chip down the road..." She also noted that the 
historical and political context of Caribana is not presented or sought out, rendering the celebration impractical as an educational experience.

When asked for her understanding of the term social inclusion, Defiant explained that it is a problematic term because it does not involve equity or accessibility in regard to who is being omitted from conversations, or what is being done to make people feel included. She referenced Indigenous land acknowledgements as being inclusive of Indigenous beliefs and rights, but it does not actually help the Indigenous community in any way. "Just because it [conversations] includes something, doesn't make it inclusive and just because it's inclusive, does not mean its equitable or accessible." She considers herself to be a member of the larger GTA community as a citizen via her participation in politics, but when it comes to "social connections", Defiant identifies with certain communities like the LGBTQ+ and University community, but always "emphasizes Black first." She sees the GTA as "very divided, usually based on race," so her sense of belonging to various communities is first and foremost influenced by her race - "I think it's just never separate, we can never omit Blackness from the conversation." Because of the racism she has faced in various spaces, Defiant is adamant about avoiding spaces and situations where Black people are not the majority demographic:

"I will not go to a place if it is like, all White, I will walk out, it's really that simple... I won't go to a party unless it's Black-run and like, predominantly Black attended. I don't put my money to things, as best as I can, if it's not Black-owned, I don't buy at the Farmers' Market from White people, I only buy from Black people, and the reason is because I get treated differently. I get treated like a human being from Black people whereas like, you know, times at the Farmers' Market where I buy from White people I'm just overlooked, I'm the last one asked for money, they just gaze over the crowd and act like I'm not there, or they charge me different prices than they charge other people."

Defiant believes it is important for people to feel welcomed in society because, "acceptance and communal interdependence, I believe, is how we're wired and no one man is able to 
accomplish what a group can do, and that collaboration is necessary... I think it's really important to feel welcome in a community so you can offer those contributions, so that you can have an impact and also so that you can reap the rewards of what groups have to offer, such as sustainable food sources, or income, or shelter, or protection." She considers equitable access to all human needs necessary "for someone to feel happy and content in the community," which may indicate that a person feels welcomed. She considers it an individual and collective obligation to make everyone feel welcomed in society and explained that individuals spark conversations about social issues and drive policy change that can allow everyone to be taken care of.

\section{A Mind Of Its Own (AMIO)}

AMIO is a 21-year-old mixed-race Black woman working towards a Bachelor of Arts degree. She is currently employed part-time and earns less than $\$ 20,000$ annually. She described her hair texture and style as "curly, mid-length, and pretty voluminous." She prefers wash-and-go styles for her natural curls. Since she has embraced her natural hair, she straightens her hair with a flat iron about once a year.

AMIO defines natural hair as, "just embracing what you're born with no matter if it's like, what the media and society says it should be, it's just embracing what you naturally have." Growing up in a predominately White neighbourhood, she learned that her hair "wasn't accepted" in society. She was always told by family members that she had "good hair" and was encouraged to wear it naturally, but would receive "ignorant comments" from peers that made her selfconscious about its natural texture, "like if I were wearing my hair like, out, like, 'Wow, your hair is so puffy,' or just like, weird comments like that." AMIO never permed her hair but she used to regularly straighten it with a flat iron until about 2011. Now, she straightens it about once a year because she feels like something different, or to see how long her hair has grown. 
AMIO's decision to go natural was influenced by her older sister who began doing research on how to care for her natural curls and sharing this information with AMIO. Deciding to wear it naturally more often also influenced their mother to stop chemically straightening her own hair. A major turning point in AMIO's natural hair journey was the birth of her two cousins, who are also mixed-race. "I just wanted like, when they were around me I wanted them to see that I would like, embrace my hair and that it was okay for them to embrace their hair too because it's beautiful and they should, they should love it and not care what other people say." She experienced a shift in ideology as she matured that led her to realize that straightening her hair for an event "to look nice [is] so backwards," and it was killing her hair. Wearing her natural hair is important to AMIO not only because she wants to be a positive role model to her cousins, but also because of, "freedom, it's like my identity, I'm not suppressing who I am, I'm just letting me be me and be free and yeah, and just to not let anyone else say what beauty is or what like, professionalism is, I'm going to make that decision for myself."

When asked how the natural hair textures of Black women are perceived in the GTA, AMIO explained,

"People aren't very educated about it. So, I feel like even if a Black woman who does have like, very kinky hair is like, wearing a weave, a lot of people won't even realize that's not her real hair. So then when she was to wear her hair like natural, people would be like, 'What? Like, what is that, what happened?' Like I have a friend and at work she wore her hair natural and everyone like, was coming up to her and being like, 'Oh that's so cool, can I touch it?' And they were all like, touching her hair and that's just, they don't realize that's not appropriate I guess because like yes, okay something it's new to you, but, I don't know, that's never appropriate so yeah. It's just like, people are very ignorant about it. So they like, they say inappropriate things or they do inappropriate things. And like, I feel like our society doesn't really like, promote keeping your hair natural."

AMIO also noted that there are not many salons in the city that "really tell you to embrace your natural hair, they just like, straighten it or cover it." She considers her hair to be a form of 
activism because, "it's going against everything that people have made me feel or have said to me or what media portrays, it's just going against that. I feel like, again like, embracing who you are no matter what people say is like, a form of activism." She believes that representation is important "to educate the whole population and it's just not like, it's not going along with it like, you're fighting it. So, by fighting it you're encouraging other people to fight it and just be themselves." AMIO considers pop culture to be a significant platform for representation. She referred to the Marvel blockbuster, Black Panther and said, "I felt so empowered watching that movie. Their costumes I thought were great because they really like, they took the cultural side of things and really embraced it like, it's again like, using your strengths [to] lift people up and educate and inspire, like it's all of that, it was great." Although AMIO is not involved with any sociopolitical movements in the GTA, she believes they serve a great purpose and, "I think we need more of it." Living in the northern part of the GTA, AMIO feels excluded from Black empowerment movements due to a lack of opportunities to participate in her neighbourhood. "It'd be nice to like, hear more about it in the news or to be able to find out what you can take part in. I guess you don't really hear, maybe you do in Toronto but like up here, you don't really hear about it."

When asked how she defines racism in the context of the GTA, AMIO explained,

"I feel like it's very swept under the rug, like we could say, 'Oh like, there's no racism in Canada, like we're so nice like, it's not like the States,' but I feel like it's all ignorance like, it's really, it's hushed about but it's there, it's definitely there. And like you can, you can feel it. But nobody talks about it. Yeah. Just like, little comments that people like, will joke or laugh or just not even realize it's racist. But they say it still."

Because AMIO believes a lot of the racism in the GTA is hidden in ignorance, she feels like she needs to do more to address it when racist comments are made in her presence. "I need to get better with that I find. Because sometimes I'm so thrown off guard or like, shocked that someone said something like, I know that this is the way people think. But I'm so shocked that I 
don't like, say it to them, which I want to be able to say it to them because like, we need to educate because that's the only way to prevent it right, and stop it." While she does not consider it a personal obligation to address such comments, "like I shouldn't have to," she does believe that educating people must take place on an individual level for people to understand. She recounted an instance at her workplace when she addressed a racial microaggression as a teaching moment but was dismissed by her co-workers:

"Through my work, we had this, it was called anti-bias training and it was focused on like, Black people and there was like a questionnaire sort of like, 'On a scale from 1 to 10 how comfortable do you feel wearing your natural hair?' So, we all filled out the answers and stuff and then the people at the table like, there was like there was a mix, there was White people, Black people, Asian, but they just kind of like brushed off the question. So, I was like, 'Oh I think we should talk about some of these to sort of just like, shed light on them', and they were like, 'Oh which one?' And I was like, 'Well specifically the one about the hair', and then I was like, 'Obviously like we're going to have different answers for this, but I think this is a pretty big issue, like in our society,' and then, so my friend, she's from Ghana so she has like very, very tight, kinky hair. And like, she tells me all the time that she doesn't feel comfortable to wear hair natural. So I guess I shouldn't have spoken for her but I was kind of speaking for both of us and I was like, 'I know I used to not feel comfortable wearing my hair and I know my friend doesn't', and then one of the White ladies at the table is just like, 'Oh yeah me too like, when I wake up in the morning and my hair is all frizzy', she's like, 'oh I can't, I feel so uncomfortable I have to like, straighten it' and she's like laughing and they're all laughing and I was kind of like, I don't think that's the same thing... like I think it's a little different... then like, I don't know like you try to bring it up and I guess I could have gone further with that but they still, they just don't really, like they're laughing and they just don't really get it."

The reaction from her co-workers made AMIO feel "very negatively" and "it's sad but it made me feel differently about the people too because like, I didn't realize that that's how their mentality is." She indicated that the conversation may have been more productive in a more diverse space with more Black people because, "when you work with people who in no way can relate to what your problems are, it's sort of hard to start that discussion without them like, making jokes because they can't relate." AMIO has faced these subtle forms of racism from a very young age. She recalled a time in elementary school when she wore her natural hair down and as she and her 
classmates were lined up, a boy told her, 'your hair is so puffy and in the way, I can't see,' and he brushed it away. AMIO then left her place in line and went to the end "so that I wouldn't be like, in the way of people." She also used to participate in dance competitions where her coaches told her that her natural curls were inappropriate for the presentation - she was instructed to curl her hair with a curling iron, which required AMIO to first straighten it with a flat iron. At many hair salons she has visited, stylists would first straighten her hair and then cut it, "they couldn't really handle it naturally, they had to change it to do it." Such instances used to make AMIO question her self-worth and think, “Oh, am I not good enough just because I have this hair?” Her mentality changed as she got older and rather than "internalize it and pretend like it didn't bother me," she began to think, "Why can they not handle my hair like, I am part of this society as well and they should be able to do it."

AMIO has also faced instances of cultural appropriation that made her feel uncomfortable. One instance occurred at her workplace when she wore Box Braids and a few non-Black coworkers said, 'Oh that's so cool, I want to get that too.' AMIO explained that she felt uncomfortable because "they're not Black in any way [and] I feel like when Black culture is celebrated in the media... people don't actually understand the cultural background behind it... so yeah, just appropriation, it's just uncomfortable because it feels either like, ignored or exploited." While she believes that Canadians "try to celebrate all cultures... and Canada does embrace sort of like, being Canadian but then also being able to celebrate your own culture and like, religion," through the Multiculturalism Act, "people still feel ways about other cultures... and again like, for me that's just like, ignorance. You don't understand like, when you don't understand, you're scared right so then that turns into hatred and then you have like, these ideals in your head that don't really 
make any sense, but you've made it make sense in your head." Therefore, AMIO cannot confidently say if The Act affects the lives of racial minorities, or not.

When asked how she understands the term social inclusion, AMIO explained, "just accepting all different cultures, religions and then again, like, not making things taboo like, making everything open to talk about so that we can educate and accept each other." Being of mixed-race, AMIO struggles to identify with race-based communities. "I feel like if I were to say like, 'I'm Black,' people would be like, 'no you're not', which I guess is partially true but it's also not true because like, my ancestors are Black. And then it's sort of the same thing, like if I were to say, 'oh I'm White', like again, I don't know, I don't identify as that, like I'm mixed." She does prefer to spend her time in other parts of the city that are more diverse because, "I feel like maybe [people in my neighbourhood] wouldn't welcome someone of darker skin than me and that's what makes me feel like I don't want to be in those spaces." When asked if she has ever been made to feel uncomfortable in her less-diverse neighbourhood, AMIO said, "No, and I think that's like, the privilege that I have where people can't tell sometimes... like I can look like I'm White." She believes it important for people to feel welcomed in society because, "people can't thrive if they don't feel accepted and like, the whole point of the human race is that we're supposed to like, love each other and uplift each other but if we're making people feel like they don't belong, how are they supposed to even start to try to succeed and grow?" She believes that people feel welcomed when "they are free to speak their mind, to wear they want to wear, to do what they want to do, to just be themselves." Furthermore, she considers it an individual obligation to try to make people feel welcomed, "you should try every day to make people feel included."

AMIO considers cultural celebrations to be a positive platform for facilitating social inclusion because they allow people to celebrate their culture together and share it with cultural 
outsiders. To those who are open-minded, they can be positive educational experiences, but to others, the effort is wasted. "I think that when you've reached a certain level of ignorance you can take it the wrong way. Like if you think of Caribana, I feel like people have like, a stereotypical idea of what it might be, or they might say like, ignorant comments, so with that I guess it's not really setting it up for education because people already have an assumption in their head." AMIO considers Caribana and the Pride Parade to be the two most negatively perceived events in the city because of the amount of backlash both events receive from the public and the police.

\section{Strength And A Mystery (SAM)}

Strength And A Mystery is a 39-year-old Black woman with a post-graduate degree. She is currently employed on a temporary/part-time basis as a Supervisor and earns between $\$ 21,000$ and $\$ 40,000$ annually. She describes her hair texture as "curlier in the front and kinky in the back", which she attributes to both of her parent's textures, her mother's being curlier and her father's being kinkier. She wears her hair in dreadlocks which are plaited and indicated that since embracing her natural hair, she never styles it in a way that would not be considered natural.

SAM defines natural hair as, "the hair you're born with without chemicals in it to change the natural texture." In elementary school she wore her hair naturally in plaits but as she got older, her mother's work schedule no longer awarded the time it took to braid SAM's hair, so she began to wear it in the popular Jheri Curl style. She was never told by any family members that she had to straighten her hair and actually received compliments when she wore it in an afro because "I maintained it so well.” When the chemical perm grew in popularity, however, her father would ask her, "Oh, why don't you do your hair like that, oh look at those girls, their hair is straight, let me take you," and it was "sometimes like a battle." SAM regularly permed her hair straight all throughout high school and was influenced to do so by her older brother who told her, "You can 
not come into high school with a Jheri Curl," because she would be teased, and her cousin who praised the ease of management of the perm. While she did not mind the perm, she still commonly wore it in braids and other Afrocentric styles so, "a lot of people might not have even known my hair was permed." She stopped perming it when she graduated from high school and the influencing factor was maturity and, “...just knowing me, knowing myself, knowing who I am... and the road I want to take" As the effects of the perm faded, her father again tried to convince her to straighten it but SAM adamantly refused to use any more chemicals in her hair. Both of her parents were fine with any of her hairstyle choices, "as long as it looked neat." They would draw attention to it only when the roots began to show and asked, "What are you doing with your hair? [Or] When are you going to get your hair done?" Having it well-maintained was the most important factor.

In her places of work, SAM has received negative comments directed towards her natural hair styles. One co-worker told her that her afro "looks like a troll's hair." A manager told her that she could not wear her hair wrapped a certain way, but once SAM explained to him that she must have it wrapped to put it up, she cannot tie it in a ponytail like other women, he allowed her to wrap it. Other people would often reach out and touch her hair without her consent out of curiosity, and SAM would have to tell them why that is not appropriate. In any instance when SAM's hair was a point of discussion, SAM would explain the reasons why she can or cannot wear it a certain way. For example, she had to explain to another manager that the uniform hats would not fit her due to the volume of her hair and so, she could not wear it. SAM has found that any situation can be mediated and resolved if she explains the legitimate reasons why she cannot satisfy a request, so she reported that there has never been an instance when her hair was an issue in the work environment. 
Is it important that SAM wear her hair naturally because, "it's just a reflection of me, it's a reflection of who I am... if anybody who really knows me or grew up with me, they would tell people, 'Yeah I don't know why she didn't do it sooner'... [the dreadlocks] just makes sense." SAM has worn dreadlocks since about 2010 and she would have gotten them earlier but a good friend who also wears locks told her, "Never wear your crown before your time." Her time came with her $30^{\text {th }}$ birthday when, "something just clicked and I knew, yeah it's time." She does not consider her decision to go natural a political statement or a form of activism because, "I just did it for myself, it's who I am," but she "will always stand for... people being natural and being true to themselves." Although SAM does not participate in any sociopolitical movements in the GTA, she used to be involved in anti-racism campaigns and various organizations when she was younger and used her teaching opportunity to educate her students on issues of racism and inequality in Canada. She chooses not to get involved with BLM because her perception of some of the representatives is that they "are not knowledgeable on what the group is supposed to stand for," and some of their behaviour "has totally discredited what the whole organization stands for." She also believes that natural hair is not necessary to be "unapologetically Black" because, "your hair doesn't define what your message is, so what your voice says can be different from how you look." When asked if she thinks "being natural" is fully accepted in the GTA, she explained,

“... I think times are changing, I find that in high schools... I see more girls wearing their hair natural, and that's not necessarily what was happening when I was in school. But I'm seeing a lot more girls wearing their natural hair and kind of embracing it, which is kind of cool, I'm liking that. In the corporate world, I don't know, I don't know too many people in that world, where I work it's never been an issue... so I'm hoping it's being more accepted. I'm hoping that people seeing more things via television and stuff, they see more different faces, they see more different styles and like... as the younger generation comes in and takes those management corporate positions then I think it'll become more accepted. Not like $100 \%$, and not everywhere, but it'll improve." 
SAM believes that the dominant group in Canadian society "doesn't understand" the natural hair textures of Black women, and "nobody knows the history behind it." When she moved to northern Quebec to teach for one year, her students thought that she was born with dreadlocks and they did not know that she was treated differently by some people in their town. She used that opportunity to educate her students on the realities of racism in Canada and the cultural history of various Afrocentric hairstyles and textures, using representation as a tool, "I would show different faces and different styles." She believes that dreadlocks in particular are negatively perceived as "dirty" and unkempt because "people just have this idea that either it's not washed, and like the comment like, 'How do you wash it?' which means it can't be washed." SAM believes that having these conversations is important because, "a lot of people, they just don't know that what they're saying is offensive... Sometimes it on us too to be open to their asking because they have no idea."

When asked what racism looks like in the GTA, SAM explained,

"It's ignorance, it's just not knowing, it's just people not understanding, and in this day and age and point in time, and depending on a persons' age, it's not wanting to learn which means that you are being ignorant because you now have an opportunity to learn, but if you don't want to then there's a problem... that's how the fire is getting stoked because people aren't taking the opportunity to learn about other cultures and other groups... to this day, racism is just lies and ignorance."

SAM believes that stereotypes and assumptions about different cultures being spread and not combatted due to ignorance is the main cause of racism in the GTA and "will be the downfall of this place." SAM tends to shed light on offensive comments when they are made in her presence in the hopes that the individual will understand the weight of their comments and cease to make them, but she understands that she cannot change anyone or stop them from making such comments. To address offensive comments, SAM will often put it into a context that the individual can identify with and "say something different to make people think," rather than react 
aggressively and escalate the situation unnecessarily. Some people have become defensive as a response to SAM making it clear that their comments were offensive, and SAM reacts by simply walking away.

SAM has faced racism in the city in different forms. She often is denied basic pleasantries and is ignored when she enters a store, but once she begins to shop, she notices employees will follow her to ensure she is not stealing. She receives unnerving looks and is made to feel "like I'm an animal in a zoo." She often feels like people believe she is unapproachable because she "[looks] like an angry Black woman," a suspicion that was confirmed when a group of employees went to another supervisor for help with a French-to-English translation even though they knew SAM's translating skills were better. She has these experiences on a regular basis and said, "unfortunately, that's my life, that's what I go through, it's not going to be the last time that that happens, it's bound to happen again." She defines some instances as "laughable" and sometimes will leave the store without purchasing her goods and not return - "I am not going to give positive reinforcement for your negative doings." SAM has also noticed a difference in perception based on how she is dressed. When she is dressed in baggy jeans or basketball shorts and is comfortable, she will receive more unnerving looks than when she is dressed in tighter jeans and a floral top.

When asked if the Multiculturalism Act affects the everyday lives of racial minorities, SAM explained,

"It's a catch... at different times and in different generations through the years, it has opened doors in different spots, I know for my parents, it opened doors and they're happy because they were able to come here... so it does open doors sometimes more than other countries, I get that, and I saw it, I was fortunate enough to attend a Swearing-In Ceremony for new Canadians and I was like, 'Yes, okay this is what it is,' but then on the other hand, it's like, 'we don't discriminate', you're carded. 'We don't discriminate', well then why did a bunch of my friends get pulled over for no reason, why did my brother get pulled over and you guys called four other squad cars on him for no reason. And it's like instances of that when you see these kinds of things happening, people randomly getting stopped or 
shot, you know, some educational programs not necessarily being in place or getting funded for any different group, then no. It's a catch right, like where is that balance?... I don't know, I can't say yes, and I can't say no."

SAM also noted, “in higher-up corporate positions, you don’t see visible minorities. In some places you don't even see women... but in more public jobs, like the public sector, you do see more visible minorities and different people, and different faces, and I think they kind of do it because they know that in the public sector, they need to have that show, they need to have it because then it's like, 'Well wait a minute... this is the public sector, we need to show that public face'." SAM observes that in lower-paying jobs, there is much more multiculturalism and less racial discrimination. However, in parts of the city that have a concentration of Black people, Black male youth tend to be described as "problem children" if they look a certain way and are treated as such by police officers because, "it's like one bad apple spoils the bunch, like a group of people who actually are bad will ruin it for everyone else."

SAM defines the term social inclusion as, "everybody, no matter race, religion, creed, um, being brought into the fold of society, you know, kind of going off of what Martin Luther King said, you know, 'I have a dream', Black, White, doesn't matter who you are, that everybody is included and everybody is able to use whatever... there are no barriers to anything, everybody has equal opportunity." She does feel like she is a member of the GTA community, but she only became aware of this sense when she moved to northern Quebec and experienced much more blatant racism. SAM is also of the mindset that even if she was made to feel unwelcomed or like she does not belong, "I'm still gonna walk with my head up, I'm still gonna make my presence known. Unless you're buying me a house somewhere else and paying my bills, sorry I ain't leaving." An important reality that she emphasized is that "the GTA is a multicultural space" and there are programs and opportunities available here for everyone to get involved in and feel like 
they are part of a community, "if you don't take advantage of the programs available or the opportunities available or even the opportunity to start your own organization... that's on you." SAM also believes that cultural celebrations are a beneficial platform to facilitate inclusion and educate cultural outsiders, but "it depends on the set-up," and what the organizers do to try and educate people on the history.

SAM considers it important that people feel welcomed in society because otherwise, "they get depressed... or they feel trapped." Choosing not to engage with their local community is an indication that someone does not feel welcomed and this could have deleterious effects on their mental wellbeing. While SAM does not believe that there is an obligation to make anyone feel welcomed, "people should just try." She considers support systems for new immigrants in the private and public sectors to be a necessary tool for facilitating inclusion and those that know people who may need help should offer their assistance wherever they can.

\section{Intricate}

When asked to describe her hair's identity, Intricate indicated that White people often describe her hair as 'intricate'. She is a 24-year-old Black woman with a Bachelor of Arts degree. She currently works in Operations and Special Projects at a University and earns between $\$ 41,000$ and \$60,000 annually. She described her natural hair texture as "tough and curly with a very strong curl pattern." At the time of the interview, Intricate wore her hair in Senegalese Twists. She indicated that since she has gone natural, she never wears her hair in a way that would not be considered natural.

Intricate defined natural hair as "anything that you're comfortable with [and] a part of your natural [unprocessed] hair is exposed." She grew up learning about "good hair" and "bad hair", 
where "good hair" is straighter and more manageable. Intricate received mixed messages about her own hair from her mother who would tell her that she had "good hair" because of its thickness but would push for Intricate to get it relaxed to make it more "manageable" and easier to style. Intricate first had her hair chemically permed when she was 3 or 4 years old until she was preadolescent, and she remembers the intense burning pain. Her hair began falling out and she developed scars on her scalp from the harsh chemicals, which led her to tell her mother she no longer wanted the perm. She explained that while her mother was not very pleased with her refusing the perms, she "never really gave me too much push back." Throughout high school, Intricate wore weaves until she was 18 when she was expected by her mother to take on more financial responsibility. As a result, she found it difficult to purchase good quality weaves and instead, switched to braids and twists. Intricate is uncomfortable with wearing her natural, unbraided hair for long periods of time because, "it takes a lot of time to get it to where I can tame it and like, wear it." That being said, wearing her hair in Afrocentric styles is important to her because "representation matters" to combat stereotypes attached to certain hairstyles. "I think it's just having have more people be comfortable wearing their hair however they feel and not feel like the pressure of having to Westernize or like, Europeanize their hair... it's just a hairstyle, it's our hair."

Intricate considers her decision to wear Afrocentric styles to be a form of activism, "not as a sign of protest but like, adding to the number of people who wear their hair naturally or just Black women who wear their hair however they feel comfortable and not feel like they have to uphold a certain standard of beauty." She considers natural hair to be an important symbol of activism because "there are not conversations happening like this about White hair, Chinese hair... There's a reason why we're having these conversations, there's a dialogue that has to be had." 
While Intricate is not involved in any sociopolitical movements in the GTA, she somewhat keeps up with news presented on social media platforms such as Twitter. Her opinion on BLM is "mixed but more so negative" because "they lack a central focus [and] I don't think they know what their end goal is." While she understands the context of the work BLM is doing, she finds it difficult to be active within it due to a lack of cohesion within the group.

When it comes to how natural Black hair is perceived in the GTA, Intricate explained that certain hair textures and styles are still negatively perceived by the non-Black community. While she praises Black women who braid their hair in intricate patterns, she believes, "if you're not Black, you look at it and think, 'That's not well done, that's not well-kept'." Furthermore, Intricate explained that negative perceptions are often attached to the hair texture more than the style. She cited corn rows as an example: "if a West African girl does it, it looks 'nappy', our natural hair grows, like, takes longer to grow, [so] the corn row might stop at like, the top of your neck. Whereas an East African girl, they're known for having longer hair, straighter hair, [so] that corn row might look a little more slick, it might look like a Kardashian's hair." She believes that negative opinions on textures stems from "European standards of beauty" and the thick hair textures of people of African descent are looked down upon "because it's not the norm." That being said, wigs and weaves have become more accepted in recent years and now, "even White people are comfortable wearing wigs because it's been popularized."

Intricate has never faced blatant racism towards her hair but gets negative attention from friends and family members when her roots begin to show. They will say things like, "maybe it's time to get your hair done, or when's the last time you got your hair done?" She sometimes receives unwanted touching of her hair from curious strangers and feels as if she is being "petted" but will often use it as a teaching moment to educate people about the texture and the process of styling. 
Intricate does not believe that "aggression is going to change anybody's mind," and usually, these are beneficial experiences.

When asked if she ever received comments about her hair that made her uncomfortable or feel embarrassed, Intricate recalled times in elementary school when she wore her hair in its natural state and was "definitely meant to feel negatively about it." It reached a point where she "would feel very negatively about my natural hair to the point where I was thinking, 'I don't want to come to school with my natural hair', or if I took out my braids on a Sunday I would make sure I would stay up, I would say, 'Mom please, please, please, comb it, brush it, make sure that it looks clean so I can go to school and feel comfortable'."

There were also instances in high school when the quality of her weave was questioned by other girls:

"I used to wear them [weaves] when I was 16, 17, 18 so I was working, I paid for the hair, but might not have been the nicest hair and people, high school people are cruel... So, you know, if, let's say we're in gym class and we'd be in the changeroom after and I go to brush my hair and the hair comes off, you know, and it's all over the floor, and girls said, 'Oh my god Sandra, you're shedding!' You want to brush it off but you're young, you know 16, 17, it hurts."

"Another time, this one girl, she said in like, the middle one of our classes like, 'Sandra, why doesn't your hair move like ours?' So stupid things, stupid things like that that comes with not understanding the hair but also just running your mouth."

"I know girls who get called out for like, their leave-outs [weave] like by, by White Girls, they'd say, 'Oh I can see where your hair is, I see where your hair starts, I get it now'... and you think, "Are they saying the same thing about me when I'm not there?"

Intricate acknowledged the harm that these kinds of comments did to her self-esteem as a teenager and realized, "saying it out loud, that probably had a lot to do with why I don't like to wear weaves anymore." She also sympathizes with Black girls currently in high school who cannot afford the best quality weaves because "they know that people know when your hair isn't as high quality or it's stiff... they have to work harder for it to maintain a standard of beauty." There is an 
additional financial aspect to maintain this standard of beauty that non-Black girls do not have to contend with. Intricate indicated that coming to terms with the financial burden of purchasing high quality weaves was "a teaching moment for myself... Why am I going to keep investing more and more when I could just invest that time in products and just understanding my own hair texture a little bit more, you know?"

Intricate prefers to keep her hair in protective styles now, such as braids or twists. She does not like to leave her hair in its completely natural state. She initially attributed this dislike to being "lazy" and not wanting to wake up early to make her hair look "presentable" before going to work. She later, however, discussed the "mental fatigue, like having to go to work or see friends who are like, 'Oh my gosh your hair!' Like, that was me all throughout high school. I was just tired. I hated it. Literally Monday morning, prepare yourself, you're going to get everybody saying, 'Oh did you do something to your hair? Did you cut it? Oh my god!' and touching your hair, literally it's mentally draining like I didn't care, I don't care to do it anymore." Rather than going into work with her natural hair, Intricate will ensure that her hair is redone over the weekend or even "take a day off on Monday and go do it." She addressed it as a "burden" and would "do anything to avoid that attention."

When asked for her perspective on racism in the context of the GTA, Intricate explained that she grew up in Ottawa so she can offer a more objective perspective on racism in Toronto:

"Toronto always wants to give this image of multiculturalism off and I don't believe it... here, I find so often people say, 'Oh my school's all Italians, my school's all Portuguese people,' so I don't believe the whole multiculturalism thing because I feel like it's very much more a mosaic as opposed to like a melting pot of people. I still hear people say extremely racist things when they think they're among friends or, you know, safe or are away from the race they might be talking about. I think like, people don't watch what they say here because they don't feel that they need to. I think racism is really heavy here. And I think a lot of it like, it's almost like it's so internalized that people don't even know they're doing it... I don't think people are as open to other cultures as they really want to believe. 
Like, the city tries but it's not tolerant... and tolerance is the minimum, it's not acceptance and there isn't even tolerance here... [racism] is a lot deeper and a lot worse than people think it is."

Intricate has experienced racism in various venues in the city. At her workplace, she often receives unnerving looks from patrons when she is not in uniform. She also recounted an instance when she and another Black co-worker were made to feel uncomfortable with their Afrocentric hair styles at their place of work:

"[Management] sent out an e-mail and it was about grooming standards. And one of them was how you have to keep your hair like maintained, it has to be up in a bun, slicked back or whatever. And I remember asking my manager like, 'Is this going to be a problem?' Like, I can't remember the exact wording in it but there was something in it that made me feel like I can't comfortably wear my twists at work. And I remember asking my manager and she's like, 'No, you're fine.' But my roommate at the time, she's of Eritrean descent and she had just gotten twists for the first time... and so that email came out after she got her twists done, and I remember her coming to me like, 'Do you think this is about me? I'm the only Black girl at the front desk,' and I said, 'Well you know what, I don't blame you for feeling like that'. I said, 'I personally went to my manager and asked, and she said no but you know, I think it can also be that I'm not guest-facing.' So, I remember her asking her boss, and her boss never gave her a straight answer, so she went to her general manager and they played it off. Apparently, somebody else wasn't wearing deodorant or something like that and they said, 'no, no it's a general thing,' but then she said after, 'I never felt comfortable wearing my hair like that,' and I remember I was the same way. A year into working there they asked me if I wanted to go to the front desk and I remember saying 'no' because I wasn't comfortable."

Although upper management assured her co-worker that they were not concerned with her hairstyle, Intricate believes, "it was just a little too coincidental." Intricate then discussed a few other times when she has experienced subtle forms of racism. She and a group of friends, the majority of whom were Black, visited an upscale restaurant for a birthday celebration and were obviously treated differently than other patrons. "Other people in our section were getting service and talked to and we weren't, and we were told to quiet down... it's the little things that made it obvious." She also received unusual attention from an associate in an expensive jewelry store that made Intricate believe, “she wasn't looking to help me, she didn't think I could buy anything in 
there." Even in big box stores she has noticed being followed by an employee and feeling as if she was being watched in case she attempted to steal. While these instances have not influenced Intricate's attendance of these spaces, she is stuck at a cross-road in deciding between "do you want to give them business or do you want to like, prove them wrong?" She considers it a personal obligation to challenge racist ideologies and will always "call people out," which has caused friction between friends when she refuses to accept their racist comments as jokes.

When asked how she understands the term social inclusion, Intricate defined it as, "the ability to be comfortable communicating in a space, whether or not you do communicate." She believes that feeling welcomed in a society is important because "the more welcomed you feel, the more comfortable you are doing what you want to do... I think you can do everything to your fullest potential when you feel welcomed and comfortable." Intricate believes it is everyone's personal obligation to make people feel as welcomed and comfortable as possible which can be demonstrated “just by smiling at someone or not being aggressive... I don’t see any harm with just being friendly." She also believes that cultural celebrations can facilitate inclusion by bringing together members of the culture being celebrated and educating those who are cultural outsiders. Intricate does not identify with any racial group in the GTA and feels excluded from the Nigerian community because, "They treat us very differently, they speak to us very condescendingly, they don't think we understand like, our language, they don't think we have the same customs, morals, values, beliefs." Rather, she identifies with the University where she attained her undergraduate degree, and the millennial community "because a lot of us are going through the same thing like the rent crisis, there's a lot more touch points that I can relate to on a broader sense." 


\section{Chapter 5 - Analysis}

In this section, the results of all six interviews will be analysed to unearth common themes on the subject matter. Similarities and differences conveyed by participant responses will be identified and critiqued. This section is divided into three components - Natural Hair, Racism in the GTA, and Social Inclusion - with the corresponding themes discussed within. Each section will begin with the definitions provided by the participants. Similar definitions will be grouped together and paraphrased, while different ones will be kept separate and compared.

\section{Natural Hair}

All six participants had similar definitions for 'natural hair' as hair that has not been treated with chemical straightening agents that alter the texture. Two of the women added another component onto what they consider 'natural hair' to mean. In addition to chemical manipulation of the hair texture, Defiant does not consider hair that is consistently manipulated with thermal tools to be natural, and Intricate added that natural hair can be "anything that you're comfortable with." None of the participants considered the application of chemical hair dye to render the hair unnatural because it does not alter the texture.

\section{Intergenerational Education - 'Good' vs 'Bad' Hair}

During the days of slavery, a shade-based hierarchy emerged that awarded better treatment and more privileges to mixed-race Black people who more closely resembled Europeans in their skin tone and physical features (Donaldson, 2012). Compared to their Black counterparts, mixedrace women had straighter, smoother hair textures, which came to be known as "good hair" (Barnett, 2016; Bellinger, 2012; Ellis-Hervey et al., 2016; Gillespie, 2013; Johnson, 2016; Johnson \& Bankhead, 2013; Johnson et al., 2017; Robinson, 2011; Rock et al., 2009; Rosette \& Dumas, 
2007; Saint-Louis, Aug. 26, 2009; Weitz, 2001; Wheeler, 2017). Because lighter-skinned Blacks were given less physically demanding jobs on the plantations, they were often given gifts by the masters, and they were more economically valued, Blacks developed an inferiority complex and sought out methods to change their physical appearance to appear more European (Barnett, 2016; Donaldson, 2012). Straightening their "nappy", "bad" hair became a popular method to attain "good" hair which was achieved through the use of harsh chemicals or hot combs. Even after the abolishment of slavery, Blacks still endured centuries of subjugation and racism (and still to this day), resulting in a deeply embedded sense of shame and yearning for acceptance in Eurocentric societies (Barnett, 2016).

Through the continued use of the terms "good hair" and "bad hair" within the Black community, it is clear that an inferiority complex towards kinkier hair has become normalized and passed down through generations. All six women that participated in this study have heard these terms, and while only two of them were pointedly told by family members that they have either "good or bad hair", all of them were made to feel like their natural hair was unacceptable to wear. Explosive learned from family members that her natural "kinky" hair was not accepted as "presentable" in Canadian society. Freeing learned from her mother's attempts to straighten her hair with alcohol that she had "bad hair." Furthermore, when Freeing wore her hair in a natural afro, her mother only spoke about it in a negative manner. Defiant learned from a number of family members that "straight hair was the only thing that was acceptable" to look "pretty", "presentable", and to "fit in" in a Eurocentric society. She was therefore pressured to chemically straighten her hair and was reprimanded by her mother when she wore it in Afrocentric styles, thus reinforcing the idea that natural hair and "Black" hairstyles are unacceptable. 
AMIO was told by her family members that she has "good hair" and was encouraged to wear it naturally, but she learned that straight hair was preferred via her peers and witnessing her mother regularly straighten her own hair. Similarly, Intricate was told that she has "good hair" by her mother because of its thickness, but she received mixed-messages because her mother began perming Intricate's hair at 3 or 4 years old to make it "more manageable" and easier to style. She therefore learned that her hair in its completely natural state requires a lot of work to "look presentable," which means smoother. SAM was never told that she has "good or bad hair" and actually received praise from family members when she wore it in an afro because she maintained it well. However, when the chemical perm became a more popular style for Black women, she was encouraged by her father, her older brother, and a cousin to perm it for aesthetic purposes and ease of management.

Whether these women were told that they have "good hair" or were led to believe that their hair was "bad hair", all six participants felt pressured to straighten their hair from a young age. All of the women discussed the intergenerational messages they have received about the negative perception of the natural hair textures of Black women in Eurocentric societies. For five out of the six women interviewed, their mother was the first person to introduce them to chemical or thermal straightening as a preferred style. Explosive, Freeing, Defiant, and Intricate had their hair chemically permed regularly from a young age and their mothers would schedule their appointments. SAM was encouraged to perm her hair by her father, but this occurred later in life when SAM was entering high school. AMIO is the only participant who was never encouraged by any family member to straighten her hair, but she referenced witnessing her mother regularly alter her own hair texture and seeing a preference for straight or loosely-curled hair in the media as the leading causes of the pressure she felt to straighten her own hair for presentability purposes. 
Most of the women interviewed were taught that straight hair is more beautiful and accepted in Canadian society and this belief negatively impacted their love for their natural hair. SAM and Defiant are the exceptions who made it clear during the interview that opinions and trends do not influence their perceptions about their own hair, although they succumbed to the pressure to perm their hair when they were young. Even when they both had their hair permed, they continued to wear their hair in Afrocentric styles such as braids, twists or wrapped at least some of the time. Both women were treated differently by their family members, however. While SAM received some push-back from her father, she was never told or asked to leave her hair straightened. Meanwhile, Defiant was told by her mother that she could not wear her hair in Afrocentric styles to events, interviews, or even to the dinner table. Defiant's decision to continue straightening her hair was a conscious decision to reduce the emotional harm inflicted upon her as she learned that assimilation would offer her more emotional and physical safety. Defiant attributes her mother's disdain for Afrocentric hair styles and Defiant's natural hair texture to "internalized anti-Blackness" within her mother's side of the family, who are Latin American. Just like people in the North, South Americans also had a shade-based hierarchy imposed upon them during colonialism (Paschel \& Sawyer, 2008), so Defiant's reference of sentiments of anti-Blackness within her family is not unusual or surprising.

While discussing the perceptions of natural hair textures in Canadian society, Explosive explained that her natural hair seems to make older Black women more uncomfortable than nonBlack people. She blames the prejudice they have received about their own hair being "messy or unkempt" for their internalized belief that natural Black hair is not beautiful or accepted in Canadian society. They then pass on these beliefs as knowledge to the younger generations, as their own parents and grandparents passed down to them. The emphasis on intergenerational 
education about hair textures confirms that European standards of beauty have transcended generational boundaries and are a major contributing factor for its continued permeation within the consciousness of the general Black community (Barnett, 2016, Donaldson, 2012, Ellis-Hervey et al., 2016, Johnson \& Bankhead, 2014). The extent of the internalized shame of their Blackness is further exemplified by Explosive's witnessing of biases against kinkier or "nappy" hair even within the Natural Hair community.

Trudy Susan (May 21, 2014), an author for Ebony, claims that the Natural Hair community, and by extension the Natural Hair Movement, emerged out of a desire to "break free from European beauty standards and embarking on a journey to embrace one's own natural hair." Furthermore, the Movement seeks to promote a culture of acceptance in which Black women can begin to think of their natural hair as beautiful, "good hair" regardless of its texture (Ellis-Hervey et al., 2016; Johnson et al., 2017). It is about "self-discovery" that gives a sense of pride and strength (Henderson, 2015). Susan (May 21, 2014) and many others within the Natural Hair community have seen one form of discrimination replaced with another, as discrimination based on hair textures became "a consequence of this new natural beauty standard." A preference for long, loosely-curled hair (i.e. Types 2 and 3 on the Andre Walker hair typing system) replaced the long-standing preference for long, straightened hair as demonstrated by the dominance of Black and mixed-race Black women with wavy or curly hair on products marketed to Black women with natural hair (Susan, May 21, 2014). Type 4 hair that is often described as kinky, coiled, and nappy continues to be seen as less attractive compared to Types 2 and 3 hair which more closely resemble European hair (Gillespie, 2013). Explosive indicated that while she has learned about some members of the Natural Hair community with Type 4 hair try to reclaim the word "kinky" to 
encourage empowerment, it remains a derogatory word as it continues to be used to describe a woman's hair in a negative manner.

Of the six participants, three of them have a natural hair texture that would be classified as Type 4 - Explosive, SAM, and Intricate. Of the remaining three, two women described their hair as a combination of curly (Type 3) and kinky (Type 4) hair - Freeing and Defiant. The remaining woman - AMIO - described her hair as "very curly." Upon observation, it was evident that her hair would be classified as Type $3 \mathrm{C}$ or perhaps combination $(3 \mathrm{~B} / 3 \mathrm{C}$ or $3 \mathrm{C} / 4 \mathrm{~A})$ on the Andre Walker system (Walker, n.d.). While every person's hair texture is unique and cannot be clearly defined by one system, understanding the participants' hair types can help to uncover some of the motives behind the racist comments and behaviour they have encountered that they believe was directed towards their hair. Defiant explained that when she styles her hair in a wash-and-go style and her curls "pop", she receives much more positive attention compared to when she styles it in an afro. AMIO has also noticed that she will receive more compliments towards her curly hair than another woman who has Type 4 hair. All of the participants have identified that there continues to be negative perceptions about Type 4 hair in the GTA and claim that this texture in particularthe posited opposite of European, straight hair - is still not fully accepted in the GTA.

\section{Natural Hair as "Resistance"}

As mentioned earlier, I was unable to recruit any participants who decided to stop straightening their hair and embrace their natural texture as a form of activism or to make a political statement, perhaps in solidarity with BLM or the Natural Hair Movement. In fact, only Defiant referred to the important role that sociopolitical movements and political activism have played in influencing her to embrace her natural hair. The reasons that Black women decide to embrace their natural texture are multifaceted and intersectional as demonstrated by the participants of this study 
(Barnett, 2016; Donaldson, 2012). Participants cited the health of their hair, being true to themselves, resisting against Eurocentric standards of beauty enforced by society but more so, their own family members, and shifting personal ideology as some of the why reasons they "went natural," demonstrating that it is unrealistic to think that anyone's decision to "go natural" is based entirely on a single reason or the same reasons. While the intersecting layers of oppression that Black women with natural hair face in the GTA have shaped their reasons for "going natural," (Lutz et al., 2011), the degree of importance that each reason has on this decision differs for each participant. Employing an Intersectionality lens is critical to understand that each participant's experiences in life are different and are processed differently, so while common motives are identified, each person's reasons for “going natural” are completely unique.

All six women discussed the lasting damage that regular chemical or heat manipulation did to their hair, thereby citing the health of their hair as one crucial factor. For Freeing in particular, embracing her natural hair was critical to her overall health as she developed fibromyalgia, a common and chronic syndrome that causes bodily pain and mental distress. She attributes its onset to the many years of the harsh chemicals of the perm seeping through her scalp into her bloodstream.

Three participants discussed the harsh chemicals found in common hair relaxers and recounted the burning pain they felt on their scalps. Freeing and Intricate were left with scars from the chemical burns, and they, along with Defiant and Explosive experienced hair loss. Burning pain and loss of hair are the two most common side effects of chemical perms as the women in Rock's documentary Good Hair (2009) reveal. The pressure to conform to Western society's standards of beauty, however, has proven to be harsher than the chemicals as Black women consider the pain and health risks to be a necessary sacrifice in order to attain a physical appearance 
that is deemed more beautiful and more appealing to potential employers and romantic partners (Barnett, 2016; Bellinger, 2012; Ellis-Hervey et al., 2016; Gillespie, 2013; Johnson, 2016; Johnson \& Bankhead, 2013; Johnson et al., 2017; Robinson, 2011; Rock et al., 2009; Rosette \& Dumas, 2007; Saint-Louis, Aug. 26, 2009; Weitz, 2001; Wheeler, 2017). Given the lasting history of oppression that Black women have endured and continue to face, concerns about the presentability of their natural hair are legitimate as Black women with natural hair continue to be discriminated against in the Toronto GTA.

The second reason that all six women referenced as a deciding factor to "go natural" is being true to themselves and their identities as Black women. All participants explained that their identities are embodied by their natural hair texture and style by saying, "it's me." Five of the women reported feeling inauthentic in some capacity when they wore their hair straight. Defiant offered the most insight into this aspect of her identity. Her natural hair "aligns with who I am at my core with the values that I've assigned to myself and with what genuinely sits right or feels right with my spiritual side." She feels "emboldened" in her natural hair and considers "going natural" a "reclamation" of one's identity and a crucial part of the self-decolonizing process. For Defiant, "going natural" helped her to overcome clinical depression that largely developed from bullying she faced while growing up as a queer Black woman in a predominately White neighbourhood. She "realized that the more I love myself, the freer I feel and happier I feel in my freest form, which is natural." The psychological effects of anxiety that Black women experience towards the presentation of their hair is well documented (Bellinger, 2007; Dash, 2006; EllisHervey et al., 2016; Gillespie, 2013; Harris-Britt et al., 2007; Johnson et al., 2017; Johnson \& Bankhead, 2013; Robinson, 2011; Sellers et al., 2006). However, there is minimal knowledge on the positive psychological effects that "going natural" can have beyond members of the Natural 
Hair community attributing a confidence boost to learning to embrace their natural hair (Hare, Mar. 27, 2013). A separate study examining the mental benefits of "going natural" would prove to be beneficial.

Deciding to embrace one's natural hair in Western society for any reason is arguably an act of resistance against the long-standing preference for straighter, smoother hair that has impacted the economic prosperity and psychology of Black women for centuries. For the women who participated in this study, "going natural" embodies a rejection of colonial, anti-Blackness ideologies that are present within themselves, their family members, the public, and mass media who all encouraged them in some way to denounce their natural hair. While none of the women embraced their natural hair specifically to make a political statement, all of them understand that natural Black hair remains politicized so sporting their natural locks is, in itself, a form of activism. Furthermore, all six women discussed the messages they received about natural Black hair from family members much more than messages they received from media sources, demonstrating that resisting against the intergenerational shame towards natural hair plays a larger role in their decisions to "go natural."

Explosive decided to continue to wear her hair natural to prove to her disapproving family members that she "can be presentable with my natural hair." Freeing considers it a "small 'p' political ideal," because, "it says you're being who you are and you're not succumbing to societal pressure of making yourself to be something that you're not." Defiant decided to "get woke" on issues of anti-Blackness and believes, "resistance is in the existence of natural hair...it's visible and tangible, and it's important for shifting representation." For AMIO, "going natural" is "going against everything that people have made me feel or have said to me or what media portrays, it's just going against that. I feel like, again like, embracing who you are no matter what people say is 
like, a form of activism." SAM explained that she "went natural" because "it's who I am," and she "will always stand for... people being natural and being true to themselves." And Intricate considers her decision to wear Afrocentric styles to be a form of activism, "not as a sign of protest but like, adding to the number of people who wear their hair naturally or just Black women who wear their hair however they feel comfortable and not feel like they have to uphold a certain standard of beauty."

The ideal of resistance demonstrated by all six women is reflective of the ideology of the Black Power Movement of the 1960s and 1970s. Just as the afro became a symbol of militancy and resistance to White supremacy and Eurocentric beauty standards that Black men and women were pressured to ascribe to in order to assimilate into White American society (Bellinger, 2007; Johnson \& Bankhead, 2013), these women are demonstrating their racial pride and rejection of oppression by refusing the perms and wearing their hair naturally. By choosing to embrace what their families and society has deemed unpresentable, unprofessional, and unappealing, these women are taking back their Black identity and undermining the legacy of slavery that has rendered Blackness the antithesis of beauty.

\section{Racism in the GTA}

When asked to define racism in the context of the GTA, all six women describe it similarly as insidious, subtle, and is most often presented in the form of ignorant comments. Explosive and Intricate also see it as "intolerance to any race that's not your race." Defiant considers racism to be a "huge problem" in the GTA and AMIO considers it to be less blatant than in the US, but "it's definitely there... you can feel it." All six women have been at the receiving end of racial microaggressions, most often in the form of unnerving looks or stares from non-Black people while out in public. All six women have also faced more blatant forms of racism and/or have been 
discriminated against because of their natural hair texture or style, which I argue is based in racism since their hair is a product of their racial heritage.

\section{Texture Discrimination}

As discussed earlier, Black women who wear their hair in its natural state have been known to experience discrimination based on the texture of their natural hair from Black and non-Black people alike (Susan, May 21, 2014). While all six participants were made to feel self-conscious or otherwise negatively about their natural hair texture, only half experienced racism overtly directed towards their natural hair. Defiant has been denied economic opportunities when she wore her hair in Afrocentric styles. She was fired from a retail job for wearing her hair in an afro, she was told by another employer that her hair looked like "slave hair" when it was styled in single braids, and she was denied an opportunity to participate in a photo shoot because her hair "didn't go with their brand, which definitely meant it wasn't straight.”

Meanwhile, AMIO's experiences with racism are subtler in the form of microinsults - rude and insensitive statements that demean a person's racial identity (Torres, Driscoll, \& Burrow, 2010). She was made to feel like her hair was inappropriate and out of place - she was told by her competitive dance coaches that her natural curls were inappropriate for the presentation, forcing her to curl it with a curling iron in a Eurocentric style, she was told by a classmate that her hair was "puffy and in the way" while in elementary school, and hairdressers would commonly straighten her hair before cutting it because "they couldn't really handle it naturally."

Finally, SAM was told by a co-worker that her afro "looks like a troll's hair," and she was told by her manager that she could not wrap her hair a certain way. However, when she explained to him that wrapping it is the equivalent of other women wearing their hair in a ponytail, he allowed 
her to wrap it a different way. While SAM indicated that these instances made her feel frustrated, Defiant and AMIO were made to question their self-worth and become self-conscious about their natural hair. These women's experiences are unfortunately not unique as is demonstrated by the number of news stories about Black women facing racism because their hair was considered unacceptable or unprofessional in the eyes of their non-Black employers and/or peers (CBC News, Mar. 10, 2016; Lee-Shanok, Apr. 8, 2016; Marychuk, Jun. 4, 2018; Stevenson, 2015 - this is not an exhaustive list).

While all six women recounted instances of racism they have faced in the GTA, only half could provide examples that were specifically directed towards their natural hair. Furthermore, AMIO could not recount any other instances of racism which she believes is a result of her "privilege" as a mixed-race Black woman who "can look like [she's] White." Since the other three women - Explosive, Freeing, and Intricate - were unable to separate discrimination towards their hair from racism towards their Blackness, and Defiant and SAM also experienced racism towards their Blackness, it is perhaps unjustifiable to examine the two separately given that curly and kinky hair textures are common for Black women whose experiences of racism and discrimination are compounded and intersectional. They were not discriminated against because of their naturally curly or kinky hair, but because they are Black women with natural hair. At this time, there is little to no information on discrimination experienced by White or very light-skinned women with curly hair to compare with their Black counterparts. That being said, Intricate explained that when nonBlack women wear Afrocentric hairstyles, they are more likely to receive praise and compliments compared to when the same style is worn by a Black woman. Cultural appropriation of Afrocentric styles was also discussed by AMIO who explained that when she wore her hair in Box Braids, non-Black co-workers expressed their desire to wear that style which made AMIO uncomfortable 
because, "I feel like when Black culture is celebrated in the media... people don't actually understand the cultural background behind it... so yeah, just appropriation, it's just uncomfortable because it feels either like, ignored or exploited." The fact that non-Black women wearing Afrocentric hairstyles is considered trendy and has been popularized in the media while Black women wearing the same style continue to be chastised for it proves that inequality is ever-present, and racism continues to be a problem in the Toronto GTA.

\section{Microaggressions - Microinsults and Microinvalidations}

As mentioned earlier, most of the participant's experiences with racism have been in the form of microaggressions. While AMIO and SAM have been at the receiving end of microinsults towards their natural hair texture, all of the women except for AMIO have also received microinsults directed towards their Blackness. One form of microinsult that some of the participants of this study have faced is the negating of their intelligence due to an underlying belief that the person of colour on the receiving end is inferior and lesser than (Torres, Driscoll, \& Burrow, 2010). Explosive and Freeing provided examples of such instances. Explosive recalled a past friend expressing surprise towards her language skills and good grades in school on more than one occasion. She was made to feel like, “because you're Black you can't be smart, or because you're Black you can't speak well..." While the individual claimed that they "were only joking" when Explosive expressed her frustration and tried to correct their ignorance, the repeated offence demonstrates that Explosive's intervention was unsuccessful. Freeing faced this kind of microinsult on more than one occasion as well. The woman distributing the graduation gowns headed towards the undergraduate level gowns before asking Freeing which degree she was getting, not considering the possibility that Freeing may be getting her PhD. Another incident involved a young person assuming that she was a student rather than a Professor when she went to 
the library to collect a rented video. Freeing explained that such instances that demean a Black person's abilities, qualifications and work ethic were a regular topic of conversation with her colleagues who were also People of Colour.

Another form of microinsult is an assumption of criminality which was experienced by Defiant, SAM and Intricate on more than one occasion. All three women reported being followed and watched by employees in retail stores, suggesting an assumption that they would attempt to steal goods. Defiant also recalled White women expressing unease with leaving their belongings in an unlocked locker in a spa facility when they saw her entering the changeroom. The hypervisibility of Black bodies when criminality is assumed is a prominent issue in the GTA as expressed by BLM (Austin et al., 2016). This form of systemic racism is what gave rise to the Movement with the acquittal of George Zimmerman for the murder of Trayvon Martin in 2012. The assumption of criminality is particularly dangerous since it has resulted in Black lives being taken at the hands of citizens and police officers who have arguably reacted unjustifiably because they believed their lives were in danger when facing Black men. Lisa Bloom, author of Suspicion Nation, pointed out that, 'The standard assumption that criminals are Black and Blacks are criminals is so prevalent that in one study, 60 percent of viewers who viewed a crime story with no picture of the perpetrator falsely recalled seeing one, and of those, 70 percent believed he was African-American. When we think about crime, we 'see Black,' even when it's not present at all." (Blow, Sept. 7, 2014).

SAM further discussed the assumption of criminality that she has witnessed in the GTA via the discriminatory policy of carding that unfairly targeted People of Colour, having Black friends and family members stopped by police officers "for no reason," and hearing Black male youth described by officers as "problem children" and are then treated as such simply because they 
are dressed a certain way. The sentiment expressed by SAM that, “...one bad apple spoils the bunch, like a group of people who actually are bad will ruin it for everyone else," coincides with what is demonstrated in studies that measure White perceptions of People of Colour committing crimes. Bloom found that, "While Whites can and do commit a great deal of minor and major crimes, the race as a whole is never tainted by those acts. But when Blacks violate the law, all members of the race are considered suspect," (Blow, Sept. 7, 2014). Much of Defiant's Equity Advocate work is centered around denouncing "violent forms of body subjectivity that we experience as Black people," which includes challenging racial stereotypes that negatively and dangerously affect the lives of Black people in the GTA. Unfortunately, issues pertaining to Black people are often ignored, negated, or nullified by members of the White public who may not accept the experiential reality of Blacks as valid because they do not see it or experience it themselves. Microinvalidations are experienced by Black women regularly, including all six participants of this study.

Explosive's feelings of being insulted were ignored by the individual who repeatedly made her feel like she was "less than" and incapable of achieving good grades in school simply because she is a Black woman. Freeing had to carefully decide how to discuss topics of inequality and identity in the classroom to not appear as "an angry Black woman," which may have impacted her credibility as an instructor with non-Black students. Defiant's explanations as to why an individual cannot touch her hair without her consent were often challenged by non-Black peers. AMIO's attempts to discuss the implications of wearing natural hair at work were nullified and treated as a joke by her non-Black co-workers, leading her to feel "brushed off.". Finally, SAM's and Intricate's attempts to challenge offensive statements made in their presence were sometimes met with defensive attitudes, suggesting that the individual did not accept their position as valid. While 
microinvalidations may seem to have less tangible consequences than microinsults, they go handin-hand. Explanations about the negative way that Black people are treated in the GTA are often ignored or downplayed by non-Black people, which allows this treatment to continue and go unchallenged and unnoticed by a large portion of the population of the GTA who hold the most power.

To challenge and combat discrimination against textured hair and racism against Black bodies, all six women emphasized representation as a critical tool both in the media and in everyday life. By wearing their hair in its natural state or in Afrocentric styles that carry negative connotations in Western society, these women have identified that they are challenging stereotypical beliefs that natural Black hair is unprofessional and unappealing, and the women that wear it are bound to be less successful than those that straighten their hair (Bellinger, 2007; EllisHervey et al., 2016; Henderson, 2015; Johnson \& Bankhead, 2013; Rosette \& Dumas, 2007; SaintLouis, Aug. 26, 2009). In their own individual ways, each woman is demonstrating that they are "unapologetically Black" in the sense that they are refusing to assimilate into a culture that denounces natural Black hair and have learned to love themselves and their natural hair in the face

of racism and the "White gaze" (Blake, Apr. 21, 2018). They have reconnected with their ancestral cultures and traditions and present themselves in ways that conveys racial pride. They are embodying Lurie Daniel Favors' claim that Black women with natural hair, "are a walking, talking political issue," (Afros and Activism, 2015). By simply existing with their natural Black hair, these women are satisfying the activism component of CRT.

\section{Social Inclusion}

When asked for their understanding of the term social inclusion, all six participants mentioned the ability for everyone to be included in society. Explosive and Freeing kept their 
definitions at that. Defiant explained that it is a problematic term because it does not involve equity or accessibility in regards to who is being omitted from conversations, or what is being done to make people feel included. AMIO expanded her definition to include, “...not making things taboo like, making everything open to talk about so that we can educate and accept each other." SAM referenced Dr. Martin Luther King Jr.'s infamous speech, I Have a Dream, and his plight to remove institutional barriers that deny certain people equal opportunity as the opposite of social inclusion. Finally, Intricate added that it also involves "the ability to be comfortable communicating in a space, whether or not you do communicate." In Canada, the federal Multiculturalism Act ('The Act') is considered to be a marker of social inclusion and Canada is praised as one of the most diverse and inclusive countries in the world (Perry, 2015). However, Perry (2015) argues that "there remains a deep divide between the ideology and practice of multiculturalism," which is demonstrated by the opinions of the participants of this study on how The Act affects the lives of racial minorities.

\section{Multiculturalism is a Myth}

While Afrocentric hairstyles and the natural hair textures of Black women are not explicitly defined as cultural markers that The Act seeks to enhance and preserve, I argue that they should be because of the longstanding history these styles have in African cultures (Bellinger, 2007). As cultural symbols, Afrocentric hairstyles should be protected, celebrated, and preserved under The Act as other cultural symbols are. Due to their understanding that the natural hair of Black women is not fully accepted in the GTA, coupled with their own experiences with racism and discrimination towards their hair, all six participants cannot say that The Act has a real effect on the day-to-day lives of racial minorities in the GTA, one of the most multicultural and supposedly welcoming cities in Canada. 
While all participants referred to the inefficiencies of The Act in transferring the ideology of multiculturalism into practice considering the heavy presence of racism, some of them also discussed the natural separation of cultural groups that occurs in the city. This was an unexpected point of discussion since I remained focused on Black versus White racism and did not consider racism that is expressed between People of Colour and even within racial groups. Explosive, Freeing, and Intricate explained that The Act is not efficiently transferred from written policy into reality because racism and the segmentation of different racial, ethnic, and cultural groups continues to characterize the GTA and keep people divided along those lines. Freeing considers this segmentation to be "one of the disadvantages of the multiculturalism policy that we have." However, she also claims that racialized communities can positively affect one's sense of comfort in a community, which can help people feel welcomed. Both Intricate and Defiant referred to multiculturalism in the GTA as "a myth" because racism and the division of people based on race, ethnicity, and culture breeds intolerance to one another. While Defiant sees some benefit to The Act in that it "opens up conversations about multiculturalism," she considers conversations to be "a small win" and are not enough. Meanwhile, Intricate claims that "I don't think people are as open to other cultures as they really want to believe. Like, the city tries but it's not tolerant... and tolerance is the minimum..." Explosive and AMIO also refer to the intolerance that is present in the everyday interactions of people (i.e. microaggressions) as evidence that The Act is ineffective. However, AMIO also believes that Canadians "try to celebrate all cultures... and Canada does embrace sort of like, being Canadian but then also being able to celebrate your own culture and like, religion."

SAM shared these same sentiments but also explained that she has seen The Act employed effectively at different points in history where new immigrants are concerned. She explained, "it 
has opened doors in different spots, I know for my parents, it opened doors and they're happy because they were able to come here... so it does open doors sometimes more than other countries." She also referred to the Trudeau government's promise and actions to settle over 25,000 Syrian refugees by the end of 2015 . That being said, she also sees racism permeating the city and People of Colour being unfairly targeted by police officers and educational programs for youths of colour "not necessarily being in place or getting funded," and therefore considers The Act to be "a catch." Freeing shares this sentiment and explained that she sees, "some individuals, yeah they're made to feel welcomed and others, no." She referred to a particular advertisement for immigration law services that she often sees on public transit that features a White baby and has wondered, "what about varying it, what about putting some diverse babies in the image or something like that, what message is being sent by that law firm about people who are supposedly welcome here?" Based on their collective opinions on The Act, it is clear that all six women who have experienced racism and/or discrimination towards their natural hair do not consider The Act to effectively "build a more integrated and inclusive society," which would reduce prejudice towards cultural/ethnic markers, such as textured hair and Afrocentric hairstyles worn by Black women.

According to the Annual Report on the Operation of the Canadian Multiculturalism Act 2016-2017, 85 percent of Canadians indicated that they "believe that ethnic and cultural diversity is a value that Canadians share to a great or moderate extent," (Government of Canada, 2018). Furthermore, the national identity of Canadians largely rests on "celebrating our differences, and welcoming and building communities through mutual respect." While two of the primary objectives of The Act is "to build an integrated, socially cohesive society," and "to improve the responsiveness of institutions to meet the needs of a diverse population," the fact that Black women 
continue to face prejudice towards their natural hair in the public sphere indicates that these objectives have yet to be fulfilled. Furthermore, the Annual Report revealed that 62 percent of Canadians reported concerns over a rise in racism, and police reported hate crime motived by race and/or ethnicity increased by 4 percent in 2016. "Hate crimes targeting the Black population were the most common type of hate crime reported and represented 15 percent ( 214 incidents) of all hate crimes motived by race and/or ethnicity in Canada," (Government of Canada, 2018). The rise in concerns about racism and hate motivated crimes against Black people can be attributed to a number of national and international factors, but the inefficiencies of The Act to mediate hatred towards racial and cultural differences cannot be ignored. Given the racism that the participants of this study have endured and witnessed taking place in the GTA, it is not surprising that they all believe that The Act does not fulfil its objectives "to build an integrated, socially cohesive society," and "to improve the responsiveness of institutions to meet the needs of a diverse population," (Government of Canada, 2018).

Perhaps the most obvious demonstration of The Act in play is in the number of cultural celebrations that take place in the GTA year-round, such as Caribana, Afro-fest, Taste of the Danforth, and so on. Although these celebrations bring people of all different nationalities and cultural backgrounds together thereby facilitating social inclusion and potentially educating cultural outsiders on other cultures, the participants of this study expressed mixed feelings towards them. Explosive posits that cultural celebrations and genuine attempts to understand other cultures can reduce segregation and promote feelings of inclusion. AMIO and Intricate share the same opinion that cultural celebrations can be a positive platform for facilitating social inclusion because they allow people to celebrate their culture together and share it with cultural outsiders. To those who are open-minded, they can be positive educational experiences, but to others, the effort is 
wasted. Freeing considers cultural celebrations a possible way to facilitate a sense of belonging and community in the GTA, but they do little to "help in terms of building something that's more long-term," to improve inclusion. SAM also believes that cultural celebrations are a beneficial platform to facilitate inclusion and educate cultural outsiders, but "it depends on the set-up," and what the organizers do to try and educate people on the history. Defiant does not believe that cultural celebrations facilitate inclusion or adequately educate cultural outsiders because, "it's not accessible to everyone." She also noted that the historical and political context of the celebrations is not presented or sought out, rendering them impractical as an educational experience.

Five of the women believe that cultural celebrations have the potential to facilitate social inclusion and educate cultural outsiders, thereby reducing ignorance and fear about the racialized 'other', but none of them are convinced that celebrations can realistically achieve this goal. The most cited reason for this downfall is the lack of real education about the political and historic contexts behind these events. Instead, they tend to be presented as fun events where people can sample different cultural foods. These celebrations do successfully bring different groups of people together and satisfy one of the objectives of The Act, but only for a short period of time. They also fail to provide an educational aspect beyond cuisine that prevents people from learning about their neighbours in the multicultural GTA, which Explosive, Freeing, and AMIO believe is the source of intolerance and hate in the city. In their perspective, fear of the unknown cultural or racial 'other' produces hate and intolerance. If cultural celebrations were altered to provide more education than they currently do, they may help to alleviate the ignorance about others that each participant blames for the culture of racism that plagues the GTA.

All six participants believe that social inclusion and feeling like one belongs where they live is an important factor that influences happiness and success, which is the underlying plight of 
most people and the goal of the Multiculturalism Act. Defiant considers "acceptance", "communal interdependence", and "accessibility" to be necessary for acquiring basic needs such as "sustainable food sources, or income, or shelter, or protection." Furthermore, they all collectively agree that there is some obligation on the individual level to make people feel welcomed in society and as Intricate explained, this can be demonstrated in the smallest form such as offering a smile to a stranger. Social inclusion can be a powerful tool used to drive policy change as Defiant explains. Having conversations where everyone feels welcomed to participate sparks social change which drives politicians to respond accordingly. By observing, respecting, and considering the intersecting oppressions that marginalized people face, laws can be altered and used as a tool to improve the effectiveness of The Act in building an integrated and socially cohesive society. 


\section{Chapter 6 - Conclusion}

As is demonstrated by the unique experiences and opinions of the participants of this study, it is impossible to come to one coherent conclusion to the question: do racist events experienced by Black women with natural hair influence their opinions on the effectiveness of the Multiculturalism Act in Canada, and is their sense of belonging to the GTA affected? Not only is the sample size of six women inadequate to base assumptions about the entire Black female population in the GTA that wear their hair naturally, but the fact that a unified conclusion could not be made for such a small sample size demonstrates the intersectional nature of their lives. It is not clear if their opinions on The Act were influenced specifically by racist experiences. Even though some of them experienced similar forms of racism, their opinions towards the Multiculturalism Act and/or the importance of social inclusion differed. There are, however, common themes that emerged out of the analysis of the interview data.

First, all six women made reference to the intergenerational education they received from parents and other family members about "good and bad hair" and how non-Black people in the GTA generally perceive natural Black hair. Given the fact that only three participants named the media as another source of this knowledge, it is safe to say that the intergenerational knowledge they received while growing up played a more important role in shaping their views on natural Black hair, as well as how they believe the GTA society perceives natural Black hair. However, all six women identified representation in the media and in real life as an important factor for pushing social change. Second, contrary to my initial belief before starting this research project, sociopolitical movements that invoke Black pride had no influence on the participant's decisions to embrace their natural hair texture, with the exception of Defiant who is heavily involved in Equity work. The health of themselves and their hair, as well as discovering and staying true to 
their identities as Black women were the two most important reasons why they decided to "go natural." Third, all six participants consider natural Black hair to be an important symbol of activism and while they do not collectively consider their decision to "go natural" a political statement, they all understand that natural Black hair embodies a resistance to the colonial legacy of racism present within their families' mindsets and a subtle culture of intolerance to racial differences in the GTA. All six participants used the term 'ignorance' to define racism in the GTA, and they collectively believe that cultural celebrations could reduce this ignorance if there was more emphasis on education.

Fourth, they all deny that the Multiculturalism Act influences the day-to-day lives of racial minorities given the fact that racism and prejudice continue to plague the city. Some participants held a more favourable view towards it as a piece of legislation that demonstrates an attempt at being welcoming, while others argued that it does not do anything. They also collectively agree that it is important for people to feel welcomed in society as it influences happiness and success, and the obligation to make people feel welcomed exists on the individual, personal level.

Based on the findings of this study, I confirm that the six participants have all personally experienced racism in the GTA, all believe that social inclusion is vital to happiness and success, and all believe that The Act is ineffective in achieving its goal of facilitating social inclusion. Improvements to The Act's transferability from ideology to practice are necessary to create a community that values and welcomes cultural and ethnic differences in the GTA.

The implications of this research can help to further understand the experiences of nonWhite immigrants in the GTA who also face racism due to their racial and/or cultural differences. While non-Black immigrants are more likely to express fondness for Canada and identify with a collective community on a national scale compared to the Black Canadian-born population 
(Gilkinson \& Sauvé, 2012), they are still discriminated against because of intolerance and ignorance. Improvements can be made to policies concerning multiculturalism, including a revamp of cultural celebrations across the country. Rather than simply providing an opportunity for people to sample different cultural cuisines, cultural celebrations can become significant tools in educating people about cultural differences and therefore decrease the ignorance that Canadians tend to show towards the culture of the racialized 'other'. I am not suggesting that these alterations would alleviate racism. Given the depth and centuries-long history of racism in Canada, these alterations may do very little, if anything to improve the culture of intolerance we see in Canada. However, it may be a sufficient place to start. 


\section{Appendix A}

\section{RYERSON \\ UNIVERSITY}

REB (2018-223)

Hi there!

My name is Jasmine Homer and I am a mixed-race Black female graduate student at Ryerson University in the Immigration and Settlement Studies department. I am contacting you to see if you might be interested in participating in a research study.

This research is being done as part of my Master's project and my supervisor's name is Dr. Cheryl Teelucksingh. The purpose of this study is to explore the use of natural hair styles among Black and mixed-race women as a form of activism, and the effects that racist events or comments directed toward their natural hair has on their sense of belonging to the Greater Toronto Area (GTA) in Ontario, Canada. By exploring these relationships, this study will question the multicultural nature and policies in the GTA, specifically the popular belief that racial and cultural differences are welcomed and celebrated. This study will also explore the role that Black and mixed-race women play in social movements in the GTA with a focus on involvement and/or solidarity with the Black Lives Matter movement, Natural Hair movement, or other social movements.

To participate, you must identify as a Black or mixed-race Black woman (this includes transwomen), be at least 18 years old, live in the Greater Toronto Area (GTA), and have stopped chemically or thermally straightening your hair or stopped wearing hair coverings such as wigs or weaves as a self-proclaimed form of activism (as you understand it). Hair extensions that add length to your natural hair (i.e. in a protective style such as braids or twists) are okay.

If you agree to participate, you will be asked to complete a demographic survey and participate in an in-person interview. Your participation will involve a one-hour long interview at an easily accessible public location in the month of $\underline{\mathbf{J u l y , 2 0 1 8}}$.

In appreciation of your time, you will receive reimbursement for travel costs to and from the interview location (i.e. TTC tokens or parking fees).

The research has been reviewed and approved by the Ryerson University Research Ethics Board (REB 2018-223).

If you are interested in more information about the study or would like to volunteer, please email jasmine.homer@ryerson.ca

Thank you,

Jasmine Homer 


\section{Appendix B}

RYERSON

UNIVERSITY

\section{Ryerson University \\ Consent Agreement \\ REB (2018-223)}

You are being invited to participate in a research study. Please read this consent form so that you understand what your participation will involve. Before you consent to participate, please ask any questions to be sure you understand what your participation will involve.

\section{AFROS, ACTIVISM, AND AFFINITY: THE POLITICIZATION OF BLACK NATURAL HAIR, RACISM, AND A SENSE OF BELONGING IN THE MULTICULTURAL GREATER TORONTO AREA.}

INVESTIGATORS: This research study is being conducted by Masters of Arts student Jasmine Homer from the Department of Immigration and Settlement Studies at Ryerson University under the supervision of Dr. Cheryl Teelucksingh from the Department of Sociology at Ryerson University.

If you have any questions or concerns about the research, please feel free to contact Jasmine Homer at jasmine.homer@ ryerson.ca or Dr. Teelucksingh at teeluck@ arts.ryerson.ca.

PURPOSE OF THE STUDY: The purpose of this study is to explore the use of natural hair styles among Black and mixed-race women as a form of activism, and the effects that racist events or comments directed toward their hair has on their sense of belonging to the Greater Toronto Area (GTA) in Ontario, Canada. By exploring these relationships, this study will question the multicultural nature and policies in the GTA, specifically the popular belief that racial and cultural differences are welcomed and celebrated. This study will also explore the role that Black and mixed-race women play in social movements in the GTA with a focus on involvement and/or solidarity with the Black Lives Matter movement, the Natural Hair movement, or other social movements. 
Homer is a mixed-race young Black woman who wears her hair naturally. This study will contribute to the completion of a Major Research Paper in partial completion of a Masters of Arts degree at Ryerson University.

A total of six (6) participants will be recruited for participation. To be eligible to participate, you must self-identify as a Black or mixed-race Black woman, be at least 18 years old, live in the Greater Toronto Area (GTA), and have stopped chemically or thermally straightening your hair or stopped wearing hair coverings such as wigs or weaves as a self-proclaimed form of activism (as you understand it). Hair extensions are fine. Formal participation in any Black Lives Matter or other social movement events is not necessary for participation in this study. Those who will be ineligible to participate will be persons who require English translation, those who continue to chemically or thermally straighten their hair or wear wigs or weaves, those who decided to embrace their natural hair for any reason other than activism (e.g. for the health of their hair), and those who live outside of the GTA.

WHAT PARTICIPATION MEANS: If you volunteer to participate in this study, you will be asked to do the following things:

\section{- LOCATION:}

O Identify a public space with private rooms that we may use to conduct the interviews that you feel comfortable attending. If you are unable to identify a location, I will suggest a public library or community centre that is easily accessible that you feel comfortable attending.

\section{- DEMOGRAPHIC INFORMATION:}

○ Complete a demographic questionnaire that will include questions about gender identity, racial identity, age, level of education, annual income range, current employment status, and citizenship status.

\section{- INTERVIEWS:}

○ You will participate in one in-person interview at the agreed upon location. A follow-up interview may be requested by the researcher to clarify any answers you have provided to ensure that the researcher is interpreting your answers correctly.

- Each interview will take approximately $\mathbf{1}$ hour, depending on the speed at which the interview questions can be answered. If for any reason you are unable or unwilling to meet for a full hour, two or more shorter interviews (30-45 minutes) will be suggested to accommodate your schedule. If you are unable or unwilling to meet with the researcher in person for any subsequent interviews, there is a possibility to conduct the interview over Skype or telephone. 
- The interview questions will address four main themes: embracing your natural Black hair as a form of activism, your connection to and general opinions on the Black Lives Matter social movement in Canada, racist events you have encountered directed towards your natural hair, and your opinions on racism and multiculturalism in the Greater Toronto Area.

\section{- RESEARCH FINDINGS:}

- You will be provided an electronic copy of the audio and written transcripts produced from your interviews and will be encouraged to review it, flag any concerns and indicate if there is any information you wish to be edited. Once the study has been approved by the Immigration and Settlement Studies panel, you will be offered an electronic copy of the completed study. Acceptance of the final document is not obligatory.

POTENTIAL BENEFITS: The potential benefit of participating in this study is that you may contribute to the advancement of societal knowledge on if, and how natural Black hair is a symbol of activism, and how racism effects Black women's sense of belonging in the multicultural Greater Toronto Area. This information will have the power to influence public perceptions on the nuances of racism that may not be common knowledge.

I cannot guarantee, however, that you will receive any personal benefits from participating in this study.

WHAT ARE THE POTENTIAL RISKS TO YOU AS A PARTICIPANT: Potential risks include psychological and/or emotional harm or discomfort that may arise from revisiting and retelling racist events that you have encountered. Such events can be traumatic and may cause you to experience Post-Traumatic Stress Disorder (PTSD) symptoms or other related psychological symptoms during the interview process. If you experience any sort of discomfort by reflecting on these unpleasant memories and do not wish to answer the related questions, you are encouraged to skip the questions or to stop participation, either temporarily or permanently. Attached to this consent form is a list of counselling services available in the Toronto GTA prepared by the researcher. Before beginning the interview, the researcher will ask if you have reviewed this list and encourage you to seek counselling services if you begin to experience any negative psychological discomforts as a result of your participation in the study.

CONFIDENTIALITY: To ensure that your privacy is protected and maintained, you will be assigned a pseudonym. Any other potentially identifying information including places of employment, the names of your employers, the names of any establishments you were visiting where a racist event occurred, and the names of those who directed racism towards you will be 
omitted and/or assigned a pseudonym. Any personally-identifying characteristics, other than your hair texture and style, will not be published.

Your name and any other identifiable information and your assigned pseudonym will be stored on an external hard drive that is password protected. Audio-recordings and notes on your interviews will be stored on a separate external hard drive that is protected by a different password with only your pseudonym to identify your responses. These hard drives will be stored in a locked room and available only to Homer and Dr. Teelucksingh. You will be audio-recorded during the course of the interviews and written transcripts of the entire recording will be produced. You reserve the right to review the transcript of your interview data and will be encouraged to identify areas that require editing. You reserve the right to retract anything said during the interview that you believe is incorrect, inappropriate, may identify you, or otherwise cause you any psychological discomfort.

All of the above-mentioned documents will only be reviewed by you, Homer (researcher), and Dr. Teelucksingh (supervisor) for the purpose of the study. These documents will be shredded and destroyed once the study has been reviewed and approved by a panel of professors and the Director of the Immigration and Settlement Studies Program at Ryerson University. The estimated date for all documents to be destroyed is the end of September, 2018.

INCENTIVES FOR PARTICIPATION: You will not be paid to participate in this study.

COSTS TO PARTICIPATION: Associated costs to participation may include transit fees and/or parking fees if you are driving to the location where the interview will be held. I will reimburse these fees in full for the duration of the interview.

VOLUNTARY PARTICIPATION AND WITHDRAWAL: Participation in this study is completely voluntary. You can choose whether to be in this study or not. If any question makes you uncomfortable, you can skip that question. You may stop participating at any time and you will still be given the reimbursements described above. If you choose to stop participating, you may also choose to not have your data included in the study. Your choice of whether or not to participate will not influence your future relations with Ryerson University or the investigators, Jasmine Homer and Dr. Cheryl Teelucksingh, involved in the research.

QUESTIONS ABOUT THE STUDY: If you have any questions about the research now, please ask. If you have questions later about the research, you may contact: 
Jasmine Homer - Student investigator

Email: jasmine.homer@ryerson.ca

Dr. Cheryl Teelucksingh - Research Supervisor

Email: teeluck@arts.ryerson.ca

Phone: 416-979-5000 ext. 6213

This study has been reviewed by the Ryerson University Research Ethics Board. If you have questions regarding your rights as a participant in this study please contact:

Research Ethics Board

c/o Office of the Vice President, Research and Innovation

Ryerson University

350 Victoria Street

Toronto, ON M5B 2K3

416-979-5042

rebchair@ryerson.ca 
AFROS, ACTIVISM, AND AFFINITY: THE POLITICIZATION OF BLACK NATURAL HAIR, RACISM, AND A SENSE OF BELONGING IN THE MULTICULTURAL GREATER TORONTO AREA.

\section{CONFIRMATION OF AGREEMENT:}

Your signature below indicates that you have read the information in this agreement and have had a chance to ask any questions you have about the study. Your signature also indicates that you agree to participate in the study and have been told that you can change your mind and withdraw your consent to participate at any time. You have been given a copy of this agreement. You have been told that by signing this consent agreement you are not giving up any of your legal rights.

Name of Participant (please print)

Signature of Participant

Date

I agree to be audio-recorded for the purposes of this study. I understand how these recordings will be stored and destroyed.

Date 
Information for mental health services provided to all participants.

*Please note that the following list was created by Homer and does not include all mental health services available within the Toronto GTA.

Centre for Addiction and Mental Health (CAMH)

Queen Street Site

1001 Queen St. W.

Toronto, ON

(416) 535-8501

College Street Site

250 College St.

Toronto, ON

(416) 535-8501

Skylark 'What's up' Walk-in Clinic

65 Wellesley St. E.

Unit \#500

Toronto, ON

YouthCan Impact Walk-in Clinic

40 Orchard View Blvd.

Unit \#102 (lower level)

Toronto, ON

Southeast Toronto Family Health Team

840 Coxwell Ave.

East York, ON

(416) 423-8800

Free over-the-phone support services:

Toronto Distress Centres

(416) 408-4357

Kids Help Phone

1-800-668-6868

Durham Crisis Line

(905) 666-0483
Assaulted Women's Helpline (416) 863-0511

Toll free: 1-866-863-0511

Distress Centre Peel

(905) 278-7208

Oakville Distress Centre

(905) 849-4541 


\section{Appendix C}

\section{DEMOGRAPHIC SURVEY}

Part of your participation in this study involves providing the following demographic information. This information will be used for research purposes only and will be destroyed following the completion of the study. You reserve the right to refuse to provide any information requested in this survey and may opt out of participation at any time. If you have any questions or concerns about this survey, please do not hesitate to ask or voice these concerns.

1. What is your preferred sex/gender association?

○ Male

Female

Transgender or Transsexual

O Other

2. What is your preferred pronoun?

$\mathrm{OHe} / \mathrm{His}$

She/Hers

They/Them/Theirs

3. What is your current age? (please write)

4. How do you racially self- identify?

$\bigcirc$ Black/African/Black Caribbean

$\bigcirc$ Mixed race

$\bigcirc$ Biracial

5. What is your current citizenship status in Canada?

*Due to the sensitive nature of this question, please feel free to opt out from answering this question if you do not wish to disclose this information.

$\bigcirc$ Citizen

○ Permanent Resident

International Student

O Other 
7. What is the highest level of education you have achieved?

(please write)

8. What is your current employment status?

$\bigcirc$ None

Temporary/part-time

Full-time

9. What is your current profession/job title (includes student)?

(please write)

10. What is your current annual income range?
○ $\$ 0-\$ 20,000$
○ $\$ 21,000-\$ 40,000$
○ $\$ 41,000-\$ 60,000$
○ $\$ 61,000-\$ 80,000$
○ $\$ 81,000+$ 


\section{Appendix D}

\section{INTERVIEW GUIDE}

Pseudonym question: What word or phrase best describes your hairs' identity?

HAIR:

1. How do you describe/define your natural hair texture and style?

2. Growing up, what messages did you receive about kinky hair and straight hair?

3. How do you define natural hair?

4. When did you stop chemically/thermally straightening your hair, or stop wearing hair coverings such as wigs/weaves?

5. Do you still sometimes alter your hair in any way that wouldn't be considered "natural"? a. If yes, why and for what occasions?

6. Was there anything in particular that led you to embrace your natural hair?

7. Why is it important to you that you wear your hair natural?

8. How do you think the natural hair textures and styles of Black women are looked at and talked about in Canadian/Toronto society?

9. Have your friends/family members ever made comments about your natural hair and the way you style it?

a. What kinds of comments?

10. Have your coworkers/managers/bosses ever made comments about your natural hair?

a. What kinds of comments?

\section{RACIST EVENTS:}

11. Have any of the comments made about your natural hair ever made you uncomfortable in any way?

12. Were you ever asked or told to change your hair style by anyone?

a. If yes, why do you think this happened?

b. Who was it that asked/told?

c. How did you respond?

13. How do you define or understand racism?

a. What do you think racism looks like?

b. Do you think people always know when they make racist comments?

c. Do you tend to correct people if they've made a racist/inappropriate comment?

i. If yes, can you tell me about one event that stands out in your mind?

ii. How did you handle the situation?

iii. How did the person respond?

iv. Were there any other people involved?

v. Were there any sort of repercussions?

14. Can you tell me about any racism you faced that you believe was a result of your natural hair? 
15. How often do you encounter racism/inappropriate comments?

a. Can you tell me about some of these events?

16. Have any of your friends/family members with natural hair told you about any racism they've encountered because of their hair?

\section{RACISM IN THE GTA:}

17. Is racism a problem in the GTA?

18. The Multiculturalism Policy is a well-known policy in Canada. How does the policy affect the lives of racial minorities in Canada?

19. Is the policy reflected in everyday life?

20. How are racial and cultural differences perceived in the GTA?

a. In public spaces?

b. In workplaces?

c. In schools?

\section{ACTIVISM:}

21. Do you consider your decision to embrace your natural hair to be a political statement or a form of activism?

a. Why do you think your natural hair acts as a form of activism?

b. Why do you think this is an important form of activism?

c. Was this your own statement of activism or was your decision inspired by a social movement, such as the Black Lives Matter movement or other movements?

22. Are you actively/formally involved in the Black Lives Matter movement or another social movement in the GTA?

a. If yes, please explain how participating in this movement (s) has influenced your own identity?

b. Based on what you know about the Black Lives Matter movement, what is your opinion on it (successes, failures, etc.)?

\section{SOCIAL INCLUSION:}

23. How do you define/understand the term 'social inclusion'?

24. Are there any communities that you identify with? (i.e. racial/ethnic/cultural, gender, etc.)

25. Please tell me about your sense of belonging as a resident of the GTA:

a. Do certain spaces feel more welcoming or unwelcoming to you than others?

b. Have you ever been made to feel unwelcome in a public place?

c. What is it about these spaces that make you feel welcomed? Unwelcomed?

d. Does the sense of feeling welcomed/unwelcomed influence your attendance of these spaces?

26. Do you think cultural celebrations (i.e. Caribana, Afro-fest, Taste of the Danforth) can facilitate social inclusion? 
27. Is it important for people to feel welcomed in society?

28. What factors indicate that a person feels welcomed in society?

29. Is there an obligation to make citizens and immigrants feel welcomed in the GTA? a. Whose obligation?

\section{CONCLUDING REMARKS:}

30. If you could say anything to your younger self, what would you say?

31 . Is there anything else you'd like to say or add about any of the themes covered that wasn't already discussed? 


\section{References}

Afros and Activism. (2015). [Panel Discussion]. Afro State of Mind. Retrieved from: http://www.afrostateofmind.com/afros-activism-natural-hair-black-power/

Austin, D. (Oct. 21, 2014). The Black Power Movements' Influence on the 'Natural Hair Movement'. Natural Haircare News. Retrieved from:

http://www.naturalhaircarenews.com/2014/10/21/the-black-power-movements-influence-on-thenatural-hair-movement/

Austin, P., Cardwell, E., Kennedy, C., \& Spencer, R. (2016). Introduction: Teaching Black Lives Matter. Radical Teacher: A Socialist, Feminist, and Anti-Racist Journal on the Theory and Practice of Teaching, 106 (106), pp. 13-17. doi: 10.5195/rt.2016.340

Barnett, M. (2016). The Politics of Black Hair: A Focus on Natural vs Relaxed Hair for AfricanCaribbean Women. Centre for Tourism \& Policy Research, 14, pp. 69-100.

Bauder, H. (2016). Possibilities of Urban Belonging. Antipode 48 (2), pp. 252-271.

Bell, D. (2016, November 13). Think Canada is better than the U.S. when it comes to racism?

Not so fast, says author of Brown. CBC News. Retrieved from:

http://www.cbc.ca/news/canada/calgary/racial-politics-canada-1.3849286

Bellinger, W. (2007). Why African-American Women Try to Obtain 'Good Hair'. Sociological Viewpoints, 23, pp. 63-72.

BlackLivesMatter.com. (n.d.). Herstory. Retrieved from:

https://blacklivesmatter.com/about/herstory/

Blake, J. (Apr. 21, 2018). Beyoncé and Lamar show what it means to be 'unapologetically Black'. CNN. Retrieved from: https://www.cnn.com/2018/04/21/us/beyonce-lamarunapologetically-black/index.html

Blow, C. M. (Sept. 7, 2014). Crime, Bias and Statistics. The New York Times. Retrieved from: https://www.nytimes.com/2014/09/08/opinion/charles-blow-crime-bias-and-statistics.html

Canadian Multiculturalism Act, Revised Statutes of Canada (1982, c.24). Retrieved from the Justice Laws Website: http://laws-lois.justice.gc.ca/eng/acts/C-18.7/page-1.html

Carney, N. (2016). All Lives Matter, but so Does Race: Black Liver Matter and the Evolving Role of Social Media. Humanity \& Society, 40(2), pp. 180-199.

CBC News. (Mar. 10, 2016). Server Akua Agyemfra, forced to alter hair, says she just wants equality. CBC News Toronto. Retrieved from: http://www.cbc.ca/news/canada/toronto/serverakua-agyemfra-forced-to-alter-hair-says-she-just-wants-equality-1.3485535 
Constitution Act, Constitutional Documents (1982). Retrieved from the Justice Laws Website: http://laws-lois.justice.gc.ca/eng/Const/page-15.html

Creswell, J. W. (2013). Research design: Qualitative, quantitative, and mixed methods approaches. (pp. 1 - 24). Thousand Oaks, CA: Sage.

Crichlow, W. (2015). Critical Race Theory: A Strategy for Framing Discussions Around Social Justice and Democratic Education. Higher Education in Transformation Conference, Dublin, Ireland, 2015, pp.187-201.

Dash, P. (2006). Black Hair Culture, Politics, and Change. International Journal of Inclusive Education 10(1), p. $27-37$.

Delgado, R. \& Stefancic, J. (1993). Critical Race Theory: An Annotated Bibliography. Virginia Law Review, 79(2), pp. 461-516.

Dixon, A. D. (2018). “What's Going On?”: A Critical Race Theory Perspective on Black Lives Matter and Activism in Education. Urban Education, 53(2), pp. 231-247.

Donaldson, C. (2012). Hair alteration practices amongst Black women and the assumption of self-hatred. NYU, SteinHardt, Applied Psychology Programme: OPUS. Retrieved from: http://steinhardt.nyu.edu/appsych/opus/issues/2012/fall/hairalteration

Dunn, A. S. (2015). Beadabees: Performing Black Hair Politics in the $21^{\text {st }}$ Century. Masters Thesis. Retrieved from UMI Dissertation Publishing. UMI No.: 1596550

Eliss-Hervey, N., Doss, A., Davis, D., Nicks, R., \& Araiza, P. (2016). African American Personal Presentation: Psychology of Hair and Self-Perception. Journal of Black Studies, 47(8), pp. 869-882.

Few, A. (2007). Integrating Black Consciousness and Critical Race Feminism into Family Studies Research. Journal of Family Issues, 28(4), pp. 452-473.

Ghosh, S. (2012). Everyday Lives in Vertical Neighbourhoods: Exploring Bangladeshi Residential Spaces in Toronto. In H. Bauder (Ed.), Immigration and Settlement: Challenges, Experiences, and Opportunities (pp. 227-246). Toronto, CA: Canadian Scholars' Press.

Gillespie, C. H. (2013). Down to the Roots: A Qualitative Analysis of the Psychological Impacts of Massages Black Women Receive Regarding their Hair. PhD Thesis. Retrieved from UMI Dissertation Publishing. UMI No.: 3587989.

Gilkinson, T. \& Sauvé, G. (2012). Recent Immigrants, Earlier Immigrants, and the CanadianBorn: Association with Collective Identities. In H. Bauder (Ed.), Immigration and Settlement: Challenges, Experiences, and Opportunities (pp. 147-170). Toronto, CA: Canadian Scholars' Press. 
Gismondi, M. J. (Aug. 18, 2017). Is racism different in Canada? Maclean's. Retrieved from: https://www.macleans.ca/society/is-racism-different-in-canada/

Government of Canada. (2018). Annual Report on the Operation of the Canadian Multiculturalism Act, 2016-2017: Multiculturalism from Now and Into the Future. Retrieved from the Government of Canada website: https://www.canada.ca/en/canadianheritage/corporate/publications/plans-reports/annual-report-canadian-multiculturalism-act-20162017.html

Graneheim, U. H., \& Lundman, B. (2004). Qualitative content analysis: Concepts, procedures and measures to achieve trustworthiness. Nurse Education Today 24(2), pp. 105-112.

Guba, E. G., \& Lincoln, Y. S. (2003). The Landscape of Qualitative Research: Theories and Issues. Thousand Oaks, CA: Sage. (pp. 253 - 291).

Hall, K. M. Q. (2016). Transnational Black Feminist Framework: Rooting in Feminist Scholarship, Framing Contemporary Black Activism. Meridians: Feminism, Race, Transnationalism, 15(1), pp. 86-105.

Hare, B. (Mar. 27, 2013). Natural Hair offers a new point of view. CNN. Retrieved from: https://www.cnn.com/2013/03/27/living/natural-hair-curly-nikki/index.html

Harris-Britt, A., Valrie, C. R., \& Kurtz-Costes, B. (2007). Perceived Racial Discrimination and Self-Esteem in African American Youth: Racial Socialization as a Protective Factor. Journal of Research on Adolescence 17(4), p. 669 - 682.

Henderson, A. (2015). Redefining the Identity of Black Women: "Natural" Hair and the Natural Hair Movement. Masters of Arts Thesis. Retrieved from UMI Dissertation Publishing. UMI No.: 1582928.

Jackson, S. J. (2016). (Re)Imagining Intersectional Democracy from Black Feminism to Hashtag Activism. Women's Studies in Communication, 39(4), pp. 375-379.

Johnson, C. (2016). Kinky, curly hair: a tool of resistance across the African diaspora. The Conversation. Retrieved from: https://theconversation.com/kinky-curly-hair-a-tool-of-resistanceacross-the-african-diaspora-65692

Johnson, T., \& Bankhead, T. (2013). Hair It Is: Examining the Experiences of Black Women with Natural Hair. Open Journal of Social Sciences 2, p. 86 - 100.

Johnson, A. M., Godsil, R. D., MacFarlane, J., Tropp, L. R., \& Goff, P. A. (2017). The "Good Hair” Study: Explicit and Implicit Attitudes Toward Black Women's Hair. Perception Institute. Retrieved from: https://perception.org/wp-content/uploads/2017/01/TheGoodHairStudyFindingsReport.pdf 
Lee-Shanok, P. (Apr. 8, 2016). Zara employee accuses store of discrimination over her hairstyle. CBC News Toronto. Retrieved from: http://www.cbc.ca/news/canada/toronto/ballah-zaradiscrimination-hairstyle- 1.3527977

Levering, B. (2006). Epistemological issues in phenomenological research: How authoritative are people's accounts of their own perceptions? Journal of Philosophy of Education 40(4), pp. $451-462$.

Marshall, M. N. (1996). Sampling for Qualitative Research. Family Practice, 13 (6), pp. 522525.

Marychuk, M. (Jun. 4, 2018). Peel school board investigating alleged "anti-black racism" post. The Brampton Guardian. Retrieved from: https://www.bramptonguardian.com/newsstory/8648732-peel-school-board-investigating-alleged-anti-black-racism-post/

Maxwell, J. (2009). The Sage Handbook of Applied Social Research. Thousand Oaks, CA: Sage. (pp. $214-253)$.

Paris, E. (Apr. 27, 2018). Canada's multiculturalism is our identity. The Globe and Mail. Retrieved from: https://www.theglobeandmail.com/opinion/article-canadas-multiculturalism-isour-identity/

Paschel, T. S. \& Sawyer, M. Q. (2008). Contesting Politics as Usual: Black Social Movements, Globalization, and Race Policy in Latin America. Souls, 10 (3), pp. 197-214.

Perry, B. (2015). Disrupting the Mantra of Multiculturalism: Hate Crime in Canada. American Behavioural Scientist, 59 (3), pp. 1637-1654.

Robinson, C. I. (2011). Hair as Race: Why “Good Hair” May be Bad for Black Females. The Howard Journal of Communications, 22, pp. 358-376.

Rock, C., Chris Rock Productions, HBO Films, (Producers) \& Stilson, J. (Director). (2009). Good Hair [Motion Picture]. Santa Monica, Calif.: Lions Gate Entertainment.

Rosette, A. S., \& Dumas, T. L. (2007). The Hair Dilemma: Conform to Mainstream Expectations or Emphasize Racial Identity? Duke Journal of Gender Law \& Policy 14, p. 407 - 421.

Saint-Louis, C. (Aug. 26, 2009). Black Hair, Still Tangled in Politics. The New York Times. Retrieved from: https://www.nytimes.com/2009/08/27/fashion/27SKIN.html

Sellers, R. M., Copeland-Linder, N., Martin, P. P., \& L'Heureaux Lewis, L. (2006). Racial Identity Matters: The Relationship between Racial Discrimination and Psychological Functioning in African American Adolescents. Journal of Research on Adolescence 16(2), p. 187 - 216. 
Stevenson, V. (Dec. 4, 2015). Demonstrators declare: Black hair is beautiful. The Toronto Star. Retrieved from: https://www.thestar.com/yourtoronto/education/2015/12/04/demonstratorsdeclare-black-hair-is-beautiful.html

Sue, D. W., Capodilupo, C. M., Torino, G. C., Bucceri, J. M., Holder, A. M. B., Nadal, K. L., \& Esquilin, M. (2007). Racial Microaggressions in Everyday Life: Implications for Clinical Practice. American Psychologist Association 62(4), p. 271 - 286.

Susan, T. (May 21, 2014). The Sad Truth About Natural Hair Discrimination. Ebony. Retrieved from: https://www.ebony.com/style/the-sad-truth-about-natural-hair-discrimination-987

Torres, L., Driscoll, M. W., \& Burrow, A. L. (2010). Racial Microaggressions and Psychological Functioning Among Highly Achieving African-Americans: A Mixed-Methods Approach.

Journal of Social and Clinical Psychology 29(10), p. $1074-1099$.

Tracy, S. J. (2010). Qualitative Quality: Eight "Big-Tent" Criteria for Excellent Qualitative Research. Qualitative Inquiry 16(10), pp. 837 - 851.

Walker, A. (n.d.). Do you know your hair type? Andre Walker Hair. Retrieved from: https://www.andrewalkerhair.com/whats-my-hair-type/

Weitz, R. (2001). Women and Their Hair: Seeking Power Through Resistance and Accommodation. Gender and Society 15(5), p. $667-686$.

Wheeler, A.N. (2017). The Radical Politics Behind Afros. I.D. Vice. Retrieved from: https://id.vice.com/en_au/article/zmn454/the-radical-politics-behind-afros

Young, D. (Feb. 26, 2018). How to be Unapologetically Black. The Root. Retrieved from: https://verysmartbrothas.theroot.com/how-to-be-unapologetically-black-1822522165 